\title{
Thermal and structural modification in transparent and magnetic germanoborate glasses induced $\mathrm{Gd}_{2} \mathrm{O}_{3}$
}

\author{
Roger Gomes Fernandes ${ }^{\mathrm{a}}$, Douglas Faza Franco ${ }^{\mathrm{a}}$, Valmor Roberto Mastelaro ${ }^{\mathrm{b}}$, Thierry Cardinal ${ }^{\mathrm{c}}$ Olivier Toulemonde $^{\mathrm{c}}$, Marcelo \\ Nalin $^{\mathrm{a}}$ \\ ${ }^{\mathrm{a}}$ São Paulo State University (Unesp), Institute of Chemistry, Araraquara, SP, Brazil \\ ${ }^{b}$ São Carlos Institute of Physics, University of São Paulo (USP), São Carlos, SP, Brazil \\ ${ }^{\mathrm{c}}$ CNRS, Université de Bordeaux, ICMCB, UMR 5026, 87 Avenue du Dr. Albert Schweitzer, Pessac Cedex, Bordeaux 33608 F, France
}

\begin{abstract}
A series of new transparent and magnetic germanoborate glasses in the system $(100-\mathrm{x})\left[60 \mathrm{GeO}_{2}-25 \mathrm{~B}_{2} \mathrm{O}_{3}-10 \mathrm{Na}_{2} \mathrm{O}-4 \mathrm{Al}_{2} \mathrm{O}_{3}-\right.$ $1 \mathrm{PbO}]-(\mathrm{x}) \mathrm{Gd}_{2} \mathrm{O}_{3}$, with $\mathrm{x}=0,1,2,5,10,15$ and $20 \mathrm{~mol} \%$, was prepared and studied with respect to their thermal and structural changes in the presence of $\mathrm{Gd}_{2} \mathrm{O}_{3}$. Based on Differential Scanning Calorimetre (DSC) analysis, a glass with $5 \%$ of $\mathrm{Gd}_{2} \mathrm{O}_{3}$ showed a high thermal stability, which progressively decreases for samples with higher content of $\mathrm{Gd}_{2} \mathrm{O}_{3}$. By the analysis of Raman and Fourier Transform Infrared (FTIR) spectra, it was possible to identify that by increasing the amount of $\mathrm{Gd}_{2} \mathrm{O}_{3}$, a progressive depolymerization of 6-membered $\mathrm{Ge}^{[\mathrm{IV}]}$ rings is promoted, concomitant with an increase of $\mathrm{Ge}^{[\mathrm{IV}]}$ tetrahedra units with non-briding oxygens. The structural analysis through the local-sensitive techniques EXAFS (Extended X-ray Absorption Fine Structure) and XANES (X-ray Absorption Near Edge Structure) showed that the short-range structural modification around the elements $\mathrm{Ge}$ and $\mathrm{Gd}^{3+}$ does not change with the addition of $\mathrm{Gd}_{2} \mathrm{O}_{3}$ and the presence of germanium four-fold coordination $\left[\mathrm{Ge}^{\mathrm{IV}}\right]$ and $\mathrm{Gd}^{3+}$ states, respectively. A simulation of the coordination number $(\mathrm{N})$, the interatomic distance $(\mathrm{R})$ of $\mathrm{Ge}-\mathrm{O}$ and $\mathrm{Gd}-\mathrm{O}$ bonds and the Debye-Waller factor was also carried out. The microstructure, after crystallization, of the sample with $15 \mathrm{~mol} \%$ of $\mathrm{Gd}_{2} \mathrm{O}_{3}$ was evaluated using optical and electron microscopes. Finally, the paramagnetic behaviour and ion probe quantification of $\mathrm{Gd}^{3+}$ ions were obtained based on magnetic susceptibility measurements.
\end{abstract}

Keywords : Magneto-optical materials ; Germanoborate glasses ; Vibrational spectroscopy ; X-ray absorption spectroscopy ; Magnetic susceptibility

*Corresponding author : São Paulo State University (Unesp), Institute of Chemistry, Araraquara, SP, Brazil E-mail address : marcelo.nalin@unesp.br

\section{Introduction}

Magneto-optical materials have been attracting the interest of researchers from a fundamental point of view due to their potential technological applications [1,2]. Although magneto-optical effects are more pronounced in crystals [3], the great difficulty in preparing monocrystals with practical dimensions limits their use in photonic devices. An alternative is to use transparent glasses and glass-ceramics with a high concentration of paramagnetic ions. A high content of unpaired electrons induces a strong paramagnetic effect, causing the glass to behave like a ferromagnetic material, even under a weak magnetic field, hence providing a range of interesting and promising applications as magneto-optical current transducer, modulator and fiber, and optical isolator $[4,5]$. Nevertheless, it is well known that the incorporation of high concentrations of rare earth into the glass matrix can promote uncontrolled devitrification during cooling, even for the most stable glasses [6], making the production of these materials challenging.

Successfully, glass systems containing high concentration $(>10 \mathrm{~mol} \%)$ of rare-earth oxides have been reported in the literature for borate [[7], [8], [9], [10]], germanate [11,12], borosilicate [13,14], aluminosilicate [15], fluorophosphates [3] and germanoborate [[16], [17], [18]] glass systems. However, their focus is mainly on the optical and magneto-optical characterization and the poorly reported structural modification in the atomic level of glasses in the presence of paramagnetic species, which is prerequisite to understand and correlate the optimal glass composition and the desired optical and magneto-optical properties of these materials.

Therefore, the present work reports the evolution of the structural modification of a novel series of transparent and magnetic germanoborate glasses in the system $\mathrm{GeO}_{2}-\mathrm{B}_{2} \mathrm{O}_{3}-\mathrm{Na}_{2} \mathrm{O}-\mathrm{Al}_{2} \mathrm{O}_{3}-\mathrm{PbO}-\mathrm{Gd}_{2} \mathrm{O}_{3}$. The characteristic temperatures and glass stability against crystallization were studied by Differential Scanning Calorimetry (DSC). The exothermal event displayed in the DSC curve corroborates the microstructure observed in the optical and electron microscopes. The structural elucidation was evaluated by the complementary vibrational spectroscopy techniques RAMAN and Fourier Transform Infrared (FTIR). X-ray Absorption Near-Edge Structure (XANES) and Extended X-ray Absorption Fine Structure (EXAFS) measurements were made to analyze the local environment of the elements Ge and Gd. A simulation from the EXAFS data was carried out to obtain the number of neighbors (N) and interatomic distance $(\mathrm{R})$ of $\mathrm{Ge}-\mathrm{O}$ and $\mathrm{Gd}-\mathrm{O}$ bonds as well as to extract important parameters, such as the Debye-Waller factor. At last, the magnetic susceptibility of $\mathrm{Gd}^{3+}$ ions was presented as a function of temperature.

\section{Materials and methods}


The following raw materials $\mathrm{GeO}_{2}$ (Alfa Aeser, 99.999\%), $\mathrm{H}_{3} \mathrm{BO}_{3}$ (Merck, 99\%), $\mathrm{Na}_{2} \mathrm{CO}_{3} \cdot \mathrm{H}_{2} \mathrm{O}(\mathrm{Sigma}, 99.5 \%), \mathrm{Al}_{2} \mathrm{O}_{3}(\mathrm{Merck}$, 99\%), $\mathrm{PbO}$ (Fluka, 99\%) and $\mathrm{Gd}_{2} \mathrm{O}_{3}$ (Aldrich, 99.9\%) were weighed in these specific proportions to prepare a series of glasses with batches of $7 \mathrm{~g}$ in the system $(100-\mathrm{x})\left[60 \mathrm{Ge}_{2} \mathrm{O}_{3}-25 \mathrm{~B}_{2} \mathrm{O}_{3}-10 \mathrm{Na}_{2} \mathrm{O}-4 \mathrm{Al}_{2} \mathrm{O}_{3}-1 \mathrm{PbO}\right]-(\mathrm{x}) \mathrm{Gd}_{2} \mathrm{O}_{3}$, with $\mathrm{x}=0,1,2,5,10,15 \mathrm{and} 20 \mathrm{~mol} \%$. First, the boric acid $\left(\mathrm{H}_{3} \mathrm{BO}_{3}\right)$ was melted in a Pt crucible until the formation of vitreous $\mathrm{B}_{2} \mathrm{O}_{3}$ according the follow reaction:

$$
\mathrm{H}_{3} \mathrm{BO}_{3(s)} \mathrm{T}<\underset{\leftrightarrow}{13} 0^{\circ} \mathrm{C} \mathrm{HBO}_{2(s)}+\mathrm{H}_{2} \mathrm{O}_{(s)} \mathrm{T}>\stackrel{130}{\rightarrow}{ }^{\circ} \mathrm{C} 1 / 2 \mathrm{~B}_{2} \mathrm{O}_{3(s)}+1 / 2 \mathrm{H}_{2} \mathrm{O}_{(\mathrm{g})}
$$

Then, the other compounds were mixed in an agate mortar, placed into the Pt crucible together with $\mathrm{B}_{2} \mathrm{O}_{3}$, and melted in an electric furnace (EDG, Brazil) at a heating rate of $10{ }^{\circ} \mathrm{C} / \mathrm{min}$ from room temperature up to $1400{ }^{\circ} \mathrm{C}$ for $2 \mathrm{~h}$. In this last process, the compound $\mathrm{Na}_{2} \mathrm{CO}_{3} . \mathrm{H}_{2} \mathrm{O}$ undergoes the following thermal decomposition :

$$
\mathrm{Na}_{2} \mathrm{CO}_{3} \cdot \mathrm{H}_{2} \mathrm{O}_{(\mathrm{s})} \stackrel{\mathrm{T}>400}{\rightarrow}{ }^{\circ} \mathrm{C} \mathrm{Na}_{2} \mathrm{O}_{(\mathrm{s})}+\mathrm{CO}_{2(\mathrm{~g})}+\mathrm{H}_{2} \mathrm{O}_{(\mathrm{g})}
$$

Afterwards, the melt was air quenched in a preheated stainless steel mold, being annealed for $2 \mathrm{~h}$ at $350{ }^{\circ} \mathrm{C}$ and slowly cooled down until room temperature. A portion of the resulting material was ground in the agate mortar, and the powders were sieved in a 20 - $\mu \mathrm{m}$ opening metal grid.

The powdered samples were studied by X-ray diffraction in an Ultima IV diffractometer (Rigatu, Japan), with $\mathrm{K} \alpha \mathrm{Cu}$ radiation $(\lambda=1.54 \AA)\left(\right.$, in the range of $2 \theta$ between 20 and $80^{\circ}$, data acquisition rate of $2 \%$ min and normal incidence angle.

Differential Scanning Calorimetry (DSC) was applied in all samples aiming to characterize the thermal events of the glasses. The DSC curves were obtained in a DSC $404 \mathrm{~F} 3$ Pegasus ${ }^{\circledR}$ calorimeter (Netzsch, Germany) at a heating rate of $10{ }^{\circ} \mathrm{C} / \mathrm{min}$ from $350{ }^{\circ} \mathrm{C}$ to $950{ }^{\circ} \mathrm{C}$ in $20 \mathrm{~cm}^{3} / \mathrm{min}$ high-purity $\mathrm{N}_{2}$ gas flow using a platinum lid-covered pan and $20 \mathrm{mg}$ of powder samples. The DSC equipment was calibrated according to Netzsch standard requirements, as described in detail in a previous work [19].

The microstructure of the sample with $15 \mathrm{~mol} \%$ of $\mathrm{Gd}_{2} \mathrm{O}_{3}$ was characterized in relation to phase morphology and elementary analysis. One piece of the sample was submitted to non-isothermal heat treatment for complete crystallization at a temperature above the endpoint of the crystallization peak, as observed in its DSC curve. Afterwards, the glass-ceramic was polished and had its microstructure observed in the optical and electronic microscopes to corroborate the results regarding the thermal events identified in the region of the crystallization peak. An elementary analysis of the phases was performed by Energy Dispersive X-ray Spectroscopy (EDS) using an Ultra Dry Thermo Scientific ${ }^{\mathrm{TM}}$ coupled to the JEOL JSM-7500F Scanning Electron Microscopy (MEV-FEG). In addition, a chemical mapping of the micrographs was created to show the distribution of the elements present in the sample. MEV/EDS samples were coated with carbon through the evaporation of graphite rods. To analyze the elements and phases, a $13 \mathrm{kV}$ beam energy was used.

The structural elucidation was carried out by the complementary spectroscopy techniques Raman and Fourier Transform Infrared (FTIR). Raman scattering spectroscopy was performed in a Jobin-Yvon Horiba LABRAM-HR-800 micro Raman spectrometer. Bulk samples were excited using a He/Ne laser excitation source tuned in $632 \mathrm{~nm}$ with acquisition data recorded by the average value of three data collections at intervals of $4 \mathrm{~cm}^{-1}$ and integration time of $100 \mathrm{~s}$ between 100 and $1200 \mathrm{~cm}^{-1}$. The vibrational spectroscopic measurements in the infrared region were performed in the absorbance mode using a Bruker Vertex 70 spectrometer, and the spectra were collected through attenuated total reflection (ATR) in the range of $400-1500 \mathrm{~cm}^{-1}$ at room temperature.

X-ray Absorption Spectroscopy (XAS) measurements were made to analyze the local environment of the elements Ge and Gd. The Germanium K-edge and Gadolinium LIII-edge X-ray absorption spectra were collected at the LNLS (National Synchrotron Light Laboratory) facility using the D04B-XAS2 beamline in transmission mode at room temperature by a Double crystal Si(111) monochromator. Ionization chambers were used to detect the incident and transmitted flux.

X-ray Absorption Near-Edge Structure (XANES) spectra at the Ge K-edge were recorded for each sample between 11050 and $11200 \mathrm{eV}$ using energy steps of $0.5 \mathrm{eV}$ around the edge. XANES spectra at the $\mathrm{Gd} \mathrm{L}_{\mathrm{III}}$-edge were recorded for each sample between 7175 and $7350 \mathrm{eV}$ using energy steps of $0.3 \mathrm{eV}$ around the edge. In both cases, to provide good energy reproducibility during the XANES data collection, the energy calibration of the monochromator was checked while collecting the sample data of the Ge metal foil and $\mathrm{Gd}_{2} \mathrm{O}_{3}$ sample, respectively.

Extended X-ray Absorption Fine Structure (EXAFS) spectra at Ge K-edge and Gd L edge and $2 \mathrm{eV}$ beyond the edge with an acquisition time of $2 \mathrm{~s}$ per point throughout the range. A range of $\mathrm{k}$ from 1.8 to $12.0 \AA^{-1}$ was selected for the calculation of the Fourier transform. For the fitting of the contribution of the first coordination shell around Ge and Gd atoms, the inverse Fourier transform was calculated (graphs not shown).

XANES spectra normalization and EXAFS spectra extraction were performed using the Multi-Platform Applications for X-Ray Absorption (MAX) software package [20,21]. The normalized XANES and EXAFS spectra were obtained using the MAX-Cherokee code, while the adjustments and the comparison between the experimental and theoretical EXAFS curves were made using the 
MAX-Roundmidnight software. Amplitude and phase shift data were calculated using the theoretical ab initio FEFF8 code with input files issued by MAX-Crystalffrev [22,23] to include the possibility of taking into account substitutions and vacancy disorders in the input crystal structures. EXAFS data fitting was made using the standard EXAFS formula as in the IXS Standard and Criteria Subcommittee Reports [24].

Finally, magnetic susceptibility was collected using a Quantum Design MPMS-7XL magnetometer in the temperature range of 5$375 \mathrm{~K}$ (for $\mathrm{x}=0.02$ and 0.10 ) or $5 \mathrm{~K}-150 \mathrm{~K}$ (for $\mathrm{x}=0.01 ; 0.05 ; 0.15$ and 0.20 ) under $1 \mathrm{~T}$ in a zero-field cooled mode.

\section{Results and discussion}

Fig. 1a shows a photograph of the synthesized glasses in this work. The samples with 0 up to $20 \mathrm{~mol}_{\%}$ of $\mathrm{Gd}_{2} \mathrm{O}_{3}$ present characteristics of vitreous phases, since they are transparent (colorless), homogeneous, bright and chemically stable, except for the sample with $20 \%$ of $\mathrm{Gd}_{2} \mathrm{O}_{3}$, which has a glass-ceramic appearance in some small regions of the piece. This behavior is often observed when part of the melt exhibits a lower cooling rate and causes the precipitation of a crystalline phase that characterizes the solubility limit of $\mathrm{Gd}_{2} \mathrm{O}_{3}$ for this composition in such preparation conditions. Fig. 1b shows the sample with $15 \mathrm{~mol}^{2}$ of $\mathrm{Gd}_{2} \mathrm{O}_{3}$ stuck to a magnet. The same behavior was observed for samples with 10 and $20 \mathrm{~mol} \%$ of $\mathrm{Gd}_{2} \mathrm{O}_{3}$, while the samples with lower concentrations of $\mathrm{Gd}_{2} \mathrm{O}_{3}$ were not attracted by the magnet, although there was a certain attraction by visual inspection. This demonstrates that the magnetism associated with the samples is proportional to the concentration of paramagnetic ions.

After synthesis, the glass state was confirmed by the X-ray diffraction technique. Fig. S1 displays the powder X-ray diffraction patterns of the samples with concentrations of 1, 5, 15 and $20 \mathrm{~mol} \%$ of $\mathrm{Gd}_{2} \mathrm{O}_{3}$. Even though the sample containing $20 \mathrm{~mol} \%$ of $\mathrm{Gd}_{2} \mathrm{O}_{3}$ had a small crystallized region, its X-ray measurement was performed on a piece that visually had a vitreous appearance. In all diffractograms, we can observe a characteristic halo of amorphous materials due to short-range periodicity.

Fig. 2 shows the DSC curves for all samples. The glass transition temperature $\left(\mathrm{T}_{\mathrm{g}}\right)$ and the onset of the crystallization peak $\left(\mathrm{T}_{\mathrm{x}}\right)$ for each composition were manually determined by the intersection of the tangents before and after the event, whose values are summarized in Table 1 . The $\mathrm{Gd}_{2} \mathrm{O}_{3}$ compound plays different roles in the structure of the glass systems under study as observed by the variation of $\mathrm{T}_{\mathrm{g}}$ as a function of $\mathrm{Gd}_{2} \mathrm{O}_{3}$ concentration. For lower amount of $\mathrm{Gd}_{2} \mathrm{O}_{3}$, $\mathrm{T}_{\mathrm{g}}$ does not show appreciable changes and slightly increases from $455{ }^{\circ} \mathrm{C}$ to $475{ }^{\circ} \mathrm{C}$ for samples with $\mathrm{Gd}_{2} \mathrm{O}_{3}$ concentration up to $5 \mathrm{~mol} \%$. As the concentration increases, the $\mathrm{T}_{\mathrm{g}}$ jumps to $553{ }^{\circ} \mathrm{C}$ and progressively rises to $655{ }^{\circ} \mathrm{C}$ for the sample with $20 \mathrm{~mol} \%$ of $\mathrm{Gd}_{2} \mathrm{O}_{3}$. $\mathrm{The} \mathrm{Gd}_{2} \mathrm{O}_{3}$-free sample exhibits a thermal event in the $675^{\circ} \mathrm{C}$ region, which could be interpreted as a second glass transition temperature. However, an additional DSC measurement (results not shown) for this sample was performed on a heating-cooling-heating program between 500 and $750{ }^{\circ} \mathrm{C}$, when no glass transition was observed on the second heating program. Thus, we characterized this event as a crystallization, which was confirmed by visual inspection of the sample inside the crucible (white color aspect) after measurement. The glass transition value generally depends on the strength of the covalent chemical bonds and the glass network connectivity, that is, the presence of $\mathrm{Gd}_{2} \mathrm{O}_{3}$ benefits the increase of the average strength in the chemical bonds, consequently producing higher network connectivity. Later in the manuscript, we describe the structural evolution based on the Raman and FT-IR spectroscopy techniques to better understand the connectivity evolution of these systems in the presence of $\mathrm{Gd}_{2} \mathrm{O}_{3}$.

The parameter $\mathrm{T}_{\mathrm{x}}-\mathrm{T}_{\mathrm{g}}$ of each composition was obtained from the DSC curves; the calculated values are presented in Table 1. The usefulness of this parameter lies in the fact that it simultaneously defines the thermal stability of the glass against crystallization as well as its working range, which makes it very important in the manufacture of optical fibers for instance. For samples with 1 and $2 \mathrm{~mol} \%$ of $\mathrm{Gd}_{2} \mathrm{O}_{3}$, the systems showed higher resistance to crystallization in the conditions and interval in which the measurements were carried out, making it impossible to notice a crystallization phenomena and calculate $\mathrm{T}_{\mathrm{x}}-\mathrm{T}_{\mathrm{g}}$ for both samples. On the other hand, a primary crystallization appeared around $730{ }^{\circ} \mathrm{C}$ for the other compositions. The glass with $5 \mathrm{~mol}^{\circ}$ of $\mathrm{Gd}_{2} \mathrm{O}_{3}$ showed high thermal stability against crystallization equal to $260{ }^{\circ} \mathrm{C}$, which progressively decreased to $83{ }^{\circ} \mathrm{C}$ when a higher concentration of $\mathrm{Gd}_{2} \mathrm{O}_{3}$ was added. Fig. 3 shows the evolution of $\mathrm{T}_{\mathrm{g}}$ and $\mathrm{T}_{\mathrm{x}}-\mathrm{T}_{\mathrm{g}}$ as a function of $\mathrm{Gd}_{2} \mathrm{O}_{3}$ concentration.

As it can be seen in Fig. 2, the exothermal event for the sample with $\mathrm{Gd}_{2} \mathrm{O}_{3}$ concentrations higher than 5 mol\% exhibits similar profiles, i.e., an intense crystallization peak followed by a shoulder after its maximum, which is characteristic of crystallization from different phases. Such phases were observed by non-isothermally heat-treating the sample with $15 \mathrm{~mol}_{\%}$ of $\mathrm{Gd}_{2} \mathrm{O}_{3}$ up to $950{ }^{\circ} \mathrm{C}$ in order to simulate the condition applied in the DSC measurement. The optical micrographs of a fully crystallized sample, Fig. 4 , show a complex microstructure with phases having different diffusion patterns. It is evidencing the presence of three different crystallite geometries: one with four-leaf clover-like shape (Phase A), one spread into the sample with a prismatic shape (Phase B), and another that could be named as Phase 3 and occupies the largest crystallized region all over the micrograph. Nonetheless, the punctual elementary SEM/EDS analysis of all these phases (arrows 1, 2 and 3 in the SEM image at the top of Fig. 5) showed that those represented by arrows 1 and 2 have the same composition (results not shown). In this case, it is suggested that their microstructure have the same crystalline phase, yet different crystallographic orientations. This argument is also supported by a chemical mapping involving all phases abovementioned, where the distribution of the elements $\mathrm{Gd}, \mathrm{O}, \mathrm{Ge}, \mathrm{Na}, \mathrm{Pub}$ and $\mathrm{Al}$ are represented separately by different colors at the bottom of Fig. 5. The characterization of each crystalline phase is beyond the scope of this work and will not be addressed herein. However, it is essential to note that the rare earth element Gd is present in large 
amount in all crystalline phases, making this composition highly appropriate for a systematic crystallization study to manufacture transparent glass-ceramics.

Raman and FTIR spectroscopies have been conducted in order to elucidate the structure and its influence on the thermal properties of the investigated glasses. Attempts to attribute the peaks were made based on relevant references of germanate [[25], [26], [27], [28], [29], [30], [31], [32], [33]], germanaborate [[34], [35], [36], [37]], germanophosphate [38], borate [39,40], and gadolinium containing germanate and borate glasses [[41], [42], [43], [44]].

The Raman spectra for glasses containing up to $20 \mathrm{~mol} \%$ of $\mathrm{Gd}_{2} \mathrm{O}_{3}$ are presented in Fig. 6. To analyze them, we separated the curves into three distinct spectral regions: low $\left(100-400 \mathrm{~cm}^{-1}\right)$, intermediate $\left(400-600 \mathrm{~cm}^{-1}\right)$ and high $(>600)$ wavenumbers. At low and intermediate wavenumbers, the spectra show a great influence of the vibrational modes of four-fold coordinated germanium $\left(\mathrm{Ge}^{[\mathrm{IV}]}\right)$, whereas at high wavenumbers the bands could be attributed based on the vibrational modes of $\mathrm{Ge}^{[\mathrm{IV}]}$ having a non bridging oxygen, and borate structures in three- and four-fold coordinations $\left(\mathrm{B}^{[\mathrm{III}]}\right.$ and $\left.\mathrm{B}^{[\mathrm{IV}]}\right)$, where the brackets refer to the coordination number of the atoms. All spectra up to $5 \mathrm{~mol} \%$ of $\mathrm{Gd}_{2} \mathrm{O}_{3}$ seem to be similar with very small changes in band intensities and positions, while for higher concentrations ( $>5 \mathrm{~mol} \%$ of $\mathrm{Gd}_{2} \mathrm{O}_{3}$ ) the changes on the band profile are more significant, corroborating the glass transition temperature evolution shown in the DSC curves. The band attributions are displayed and discussed below.

At low wavenumbers, there are two bands, one with very low intensity and another centered at 210 and $295 \mathrm{~cm}^{-1}$. Upon the addition of $\mathrm{Gd}_{2} \mathrm{O}_{3}$, both bands present slight changes in their intensity and position. Together with two other bands occurring simultaneously at high frequencies, these bands can be associated with the presence of $\mathrm{Ge}^{[\mathrm{IV}]}$ with one $\left(\mathrm{Q}^{3}\right)$ or two $\left(\mathrm{Q}^{2}\right)$ non-bridging oxygen $(\mathrm{NBO})$ [30,31]. The band at $210 \mathrm{~cm}^{-1}$ can also be correlated to the vibrational mode of $\mathrm{Pb}$ atoms in the matrix [32]. However, the lead concentration in our systems is so low that the increases in intensity, especially those observed at $295 \mathrm{~cm}^{-1}$, coincide with the rapid formation of $\mathrm{Q}^{2}$ units at higher frequency (band at $788 \mathrm{~cm}^{-1}$ ). A third and very low-intensity band around $360 \mathrm{~cm}^{-1}$ can attributed to the deformation of $\mathrm{Ge}$ atoms in the matrix [8,11], which becomes evident for samples with $\mathrm{Gd}_{2} \mathrm{O}_{3}$ concentrations higher than $15 \mathrm{~mol} \%$. Such attribution in $360 \mathrm{~cm}^{-1}$ is supported by experimental observations on the intermediate frequencies regarding changes in intensity (shoulder at 535 and $605 \mathrm{~cm}^{-1}$ ). A second attribution for this band can be due to the symmetrical stretching of the GdO-Gd bonds [45]. Fig. S2 shows the Raman spectrum of the precursor $\mathrm{Gd}_{2} \mathrm{O}_{3}$ that shows an intense peak in $360 \mathrm{~cm}^{-1}$. No reference considering the position of Ge-O-Gd bonds was found, thus making it impossible to ascertain whether such bond exist in the glass network.

In the range of $400-650 \mathrm{~cm}^{-1}$, the $\mathrm{Gd}_{2} \mathrm{O}_{3}$-free sample presents a broadband with its maximum near $455 \mathrm{~cm}^{-1}$, followed by two shoulders in the right tail side, one at 535 and another at $605 \mathrm{~cm}^{-1}$. The profile of this broadband is characteristic and can be observed in other germanates $[26,29,38]$ and germanoborate glasses [35,37]. The vibrational modes at 455,535 and $605 \mathrm{~cm}^{-1}$ are respectively assigned to the symmetrical stretching of Ge-O-Ge bonds in 4- or 6-membered rings of $\mathrm{Ge}^{[\mathrm{IV}]}$ in a tetrahedron arrangement, the breathing motion of bridging oxygen in 3-membered rings of $\mathrm{Ge}^{[\mathrm{IV}]}$ tetrahedron and the bending modes of $\mathrm{Ge}-\mathrm{O}-\mathrm{Ge}$ bonds [[25], [26], [27], [28]]. For $\mathrm{Gd}_{2} \mathrm{O}_{3}$ concentrations higher than $5 \mathrm{~mol} \%$, the maximum at $455 \mathrm{~cm}^{-1}$ decreases significantly and moves to high wavenumbers until it forms a shoulder on the left side of the band, which becomes evident for the sample with the highest concentration of $\mathrm{Gd}_{2} \mathrm{O}_{3}(20 \mathrm{~mol} \%)$. At the same time, the shoulder from $535 \mathrm{~cm}^{-1}$ to $545 \mathrm{~cm}^{-1}$ shifts to high wavenumber and has its intensity increased, acquiring the shape of a peak in the central region of the band, especially for samples with $\mathrm{Gd}_{2} \mathrm{O}_{3}$ concentrations higher than $15 \mathrm{~mol} \%$. The shoulder at $605 \mathrm{~cm}^{-1}$ presents changes in its intensity, besides a very small shift to low wavenumber. This suggests the occurrence of a progressive depolymerization of higher-membered rings upon the addition of $\mathrm{Gd}_{2} \mathrm{O}_{3}$, thus forming 3-membered rings of $\mathrm{GeO}_{4}$ tetrahedra that become more dominant in the network. The overall changes in this band (intensity and position of the attributions at 455,535 and $605 \mathrm{~cm}^{-1}$ ) as a function of $\mathrm{Gd}_{2} \mathrm{O}_{3}$ concentration is better visualized by normalizing the area in the spectral region of $350-650 \mathrm{~cm}^{-1}$ and performing a deconvolution of this band in three Gaussian peaks, as shown in Fig. $7 \mathrm{a}-\mathrm{b}$.

As already mentioned and according to Fig. $7 \mathrm{~b}$, a shift to high wavenumber can be seen for the bands at 455 and $535 \mathrm{~cm}^{-1}$. The vibrations in this spectral region are coupled with each other and highly dependent on the Ge-O-Ge average angle distribution $(\alpha)$ along the $\mathrm{Ge}^{[\mathrm{IV}]}$ tetrahedral as well as the degree of network depolymerization [27]. These shifts are expected to occur as a result of the depolymerization of higher-membered rings and a rise in the numbers of 3-membered rings due to a reduction in $\alpha$ [27,30]. Furthermore, the formation of small-membered rings in distorted or planar forms causes a lengthening of the average $\mathrm{Ge}-\mathrm{O}$ bonds and local densification of the network, which in turn promotes a more rigid or strained network [30,31]. This is evidenced by the narrowing of the band at $535 \mathrm{~cm}^{-1}$, the increase in intensity of the bending mode at $605 \mathrm{~cm}^{-1}$ and its slight shift to low wavenumber [30]. Additionally, we do not rule out the influence of $\mathrm{Gd}-\mathrm{O}$ in the shifting of the band at $575 \mathrm{~cm}^{-1}$, however, it is quite complicated to assign any contribution more precisely.

In contrast, the shoulder at $605 \mathrm{~cm}^{-1}$ could be attributed to the stretching vibration of connected $\mathrm{GeO}_{6}$ modes due to the conversion of $\mathrm{Ge}^{[\mathrm{IV}]}$ to $\mathrm{Ge}^{[\mathrm{VI}]}$ coordination, as shown by a number of authors [29,[33], [34], [35],37]. The Raman bands are usually assigned based on theoretical calculations of the systems under study and a comparison with the same vibrational mode in their crystalline structure. In this case, a crystalline reference to assign the Raman band to the $\mathrm{Ge}^{[\mathrm{VI}]}$ coordination is found in crystals of Rutila, which has an intense Raman band at $\sim 713 \mathrm{~cm}^{-1}[30,46]$. Therefore, the assignment of the band at $605 \mathrm{~cm}^{-1}$ to the stretching vibration of $\mathrm{Ge}-\mathrm{O}-\mathrm{Ge}$ in the $\mathrm{Ge}^{[\mathrm{VI}]}$ coordination is not expected to be observed at low wavenumbers and seems to be unlikely. 
In the region of high wavenumbers, we can see low-intensity bands that extend from 690 to $960 \mathrm{~cm}^{-1}$, Fig. 6 . Those bands are not easily assigned because of the overlapping of different vibrational modes from the borate structure and the germanate units with non-bridging oxygen (NBO). As aforementioned, the spectrum in this interval has no significant change up to $5 \mathrm{~mol}_{\%}$ of $\mathrm{Gd}_{2} \mathrm{O}_{3}$. We can also observe a very low-intensity band centered at $700 \mathrm{~cm}^{-1}$, followed by a unique band with distinct small peaks at 775 , 800 and a third band centered at $960 \mathrm{~cm}^{-1}$. The bands at 700 is assigned to vibrational modes of metaborate groups [34,39] and the bands at $775 \mathrm{~cm}^{-1}$ and 960 together are assigned to $\mathrm{B}^{[\mathrm{III}]}$ rings with one or two $\mathrm{B}^{[\mathrm{IV}]}$ units [34,35,39], while he peak at $810 \mathrm{~cm}^{-1}$ is attributed to boroxol rings [34,35]. Two other additional contributions in the spectral region between 750 and $880 \mathrm{~cm}^{-1}$ are considered in this work. These vibrational modes are due to the presence of $\mathrm{Ge}^{[\mathrm{IV}]}$ tetrahedra with two and one non-briding oxygens $\left(\mathrm{Q}^{2}\right.$ and $\mathrm{Q}^{3}$ units) at 788 and $862 \mathrm{~cm}^{-1}$, respectively [26]. Although these bands are not directly evident in $\mathrm{Gd}_{2} \mathrm{O}_{3} \mathrm{concentrations}$ below $5 \mathrm{~mol} \%$, the existence of the bands at 210 and $295 \mathrm{~cm}^{-1}$ suggests that they are present at low concentrations. Beyond the addition of $\mathrm{Gd}_{2} \mathrm{O}_{3}$, the spectral region between 650 and $1000 \mathrm{~cm}^{-1}$ becomes a single band with a progressive increase in its intensity simultaneously with a band decrease in the intermediate region of the spectrum $\left(455 \mathrm{~cm}^{-1}\right)$. We attribute this substantial intensity increase to the formation of $\mathrm{Q}^{2}$ and $\mathrm{Q}^{3}$ units due to the depolymerization of 4- or 6-membered rings. Such depolymerization of the network of germanate and germanoborate glasses network is observed in the presence of the alkalis $\mathrm{R}_{2} \mathrm{O}(\mathrm{R}=\mathrm{Na}, \mathrm{K}, \mathrm{Rb}, \mathrm{Cs})[26,33$ ].

Complementary, D. di Martino et al. [33] showed that in the alkalis-germanate glass with concentrations of $\mathrm{Na}, \mathrm{K}, \mathrm{Rb}$ and $\mathrm{Cs}$ higher than $10 \mathrm{~mol} \%$, the band in the region of $744-746 \mathrm{~cm}^{-1}$, named band X, is attributed to the presence of $\mathrm{Ge}^{[\mathrm{V}]}$ or $\mathrm{Ge}^{[\mathrm{VI}]}$ polyhedral. In our spectrum, this frequency is located in the valley after the maximum of the peak centered at $700 \mathrm{~cm}^{-1}$ for the samples with less than $5 \mathrm{~mol} \%$ of $\mathrm{Gd}_{2} \mathrm{O}_{3}$. For the other samples, this valley no longer exists and becomes part of the main band ranging from 650 $1000 \mathrm{~cm}^{-1}$. Therefore, at this point we can speculate that the peak centered at $700 \mathrm{~cm}^{-1}$ becomes a shoulder in the lowest left tail of the band as a result of the formations of high-coordination germanium $\left(\mathrm{Ge}^{[\mathrm{V}]}\right.$ or $\left.\mathrm{Ge}^{[\mathrm{VI}]}\right), \mathrm{Q}^{2}$ units or contributions of both vibrational modes. However, later on in the manuscript we demonstrate, based on EXAFS simulation, that all compositions studied here only present the element $\mathrm{Ge}$ in its four coordination. Besides, the increase in band intensity in the $650-1000 \mathrm{~cm}^{-1}$ region may also be related to the conversion of boroxol rings into tetraborate units $\left(\mathrm{B}^{[\mathrm{III}]}\right.$ for $\left.\mathrm{B}^{[\mathrm{IV}]}\right)[36,37,39,40]$, although such conversion occurs only in a tiny fraction according to the infrared spectroscopy results subsequently shown.

Assumptions can be made regarding the connectivity between germanate and borate structural units. The symmetrical stretching of Ge-O-B bonds should occur at $450 \mathrm{~cm}^{-1}$ [35], being so far assigned as symmetrical stretching of Ge-O-Ge bonds in the 4- or 6membered rings of the $\mathrm{GeO}_{4}$ tetrahedron. Furthermore, these specific bonds were not identified in the Raman spectra of other borogermamante glasses [37].

Since some expected vibrational modes of the matrix were not observed in the Raman spectra, we used infrared spectroscopy (FTIR) in an attempt to examine the presence of the corresponding vibrational modes. The absorption spectra in the infrared (IR) range for samples containing up to $20 \mathrm{~mol} \%$ of $\mathrm{Gd}_{2} \mathrm{O}_{3}$ are presented in Fig. 8. Nine vibrational modes were identified in the spectral region of $400-1500 \mathrm{~cm}^{-1}$ and were subsequently divided into four well-defined subregions so as to assign and describe their behavior according to the increase of $\mathrm{Gd}_{2} \mathrm{O}_{3}$ concentration.

It is possible to note a broadband between 400 and $630 \mathrm{~cm}^{-1}$ with its maximum centered at $525 \mathrm{~cm}^{-1}$ and one shoulder at the lowfrequency region at $438 \mathrm{~cm}^{-1}$. These signatures are attributed to the symmetric stretching and bending modes of $\mathrm{Ge}-\mathrm{O}-\mathrm{Ge}$ bonds [[33], [34], [35]]. This band remains unchanged for samples containing up to $2 \mathrm{~mol} \%$ of $\mathrm{Gd}_{2} \mathrm{O}_{3}$. As this concentration of $\mathrm{Gd}_{2} \mathrm{O}_{3}$ increases, the shoulder located at $438 \mathrm{~cm}^{-1}$ is no longer observed in the conditions of measurement, while the band centered at $525 \mathrm{~cm}^{-1}$ until $557 \mathrm{~cm}^{-1}$ becomes narrower and shifts to high wavenumbers. The non-observation of the shoulder at $438 \mathrm{~cm}^{-1}$ for samples with $\mathrm{Gd}_{2} \mathrm{O}_{3}$ concentrations higher than $5 \mathrm{~mol} \%$ of $\mathrm{Gd}_{2} \mathrm{O}_{3}$ is related to the depolymerization of higher-membered rings. These results are similar to those observed in the Raman spectra for in this same region.

A broad peak ranging from $630-950 \mathrm{~cm}^{-1}$ characterizes the subsequent event. In particular, both germanium- and boron-oxygen bonds are actives in this spectral region, becoming a complex assignment upon the addition of $\mathrm{Gd}_{2} \mathrm{O}_{3}$. These brad peak demonstrate no significant changes for samples containing up to $2 \%$ of $\mathrm{Gd}_{2} \mathrm{O}_{3}$, and is assigned with a peak centered at $785 \mathrm{~cm}^{-1}$ and two shoulders on the left side with their maximum located at $680 \mathrm{~cm}^{-1}$ and $660 \mathrm{~cm}^{-1}$, respectively. The peak at $785 \mathrm{~cm}^{-1}$ is the asymmetric stretching of Ge-O-Ge bonds in the $\mathrm{Ge}^{[\mathrm{IV}]}$ tetrahedra. The first shoulder located at $680 \mathrm{~cm}^{-1}$ is related to the bending vibration of $\mathrm{B}-\mathrm{O}-\mathrm{B}$ in $\mathrm{BO}_{3}$ units [[33], [34], [35]], whereas the second one is widely attributed in the literature to the stretching of Ge-O-Ge bonds in the $\mathrm{Ge}^{[\mathrm{VI}]}$ coordination [[41], [42], [43], [44]]. However, it can also be manifested by the presence of NBO-containing germanium tetrahedra [36,37], which is probably the case in this work. For $\mathrm{Gd}_{2} \mathrm{O}_{3}$ concentrations higher than 2 mol\%, the peak centered at $785 \mathrm{~cm}^{-1}$ progressively decreases, forming a shoulder at the right tail of the band. Simultaneously, the shoulder at $660 \mathrm{~cm}^{-1}$ until $677 \mathrm{~cm}^{-1}$ has its relative intensity increased, assuming the form of a peak that shifts to high wavenumbers. The shoulder located at $680 \mathrm{~cm}^{-1}$ is no longer observed, possibly due to the overlapping of the other two vibrational modes. The decrease and downshift of the peak centered at $785 \mathrm{~cm}^{-1}$ as a result of the germanium network depolymerization is expected [36,37]. Consequently, it occurs the formation of $\mathrm{Ge}_{-} \mathrm{O}^{-}$bonds, which is in agreement with the Raman spectra interpretation. Thus, the rise in the band near $680 \mathrm{~cm}^{-1}$ cannot be merely associated with the coordination change from $\mathrm{Ge}^{[\mathrm{IV}]}$ to $\mathrm{Ge}^{[\mathrm{VI}]}$. The manifestation of $\mathrm{Ge}^{\mathrm{V}}$ $\mathrm{O}^{-}$bonds and the bending modes of $\mathrm{B}-\mathrm{O}-\mathrm{B}$ in $\mathrm{B}^{[\mathrm{III}]}$ units together must also be considered.

In the central region of the spectrum, near $1100 \mathrm{~cm}^{-1}$, a broad and very low-intensity band is observed for the samples containing up to $10 \mathrm{~mol} \%$ of $\mathrm{Gd}_{2} \mathrm{O}_{3}$, and three very low-intensity peaks at 990,1030 and $1055 \mathrm{~cm}^{-1}$ progressively become evident for 
concentrations with 15 and $20 \mathrm{~mol} \%$ of $\mathrm{Gd}_{2} \mathrm{O}_{3}$ (see dashed red box magnification in Fig. 8). Such band is characteristic of B-O stretching in $\mathrm{B}^{[\mathrm{IV}]}$ units $[35,36,43,44]$. This trend suggests that $\mathrm{Gd}_{2} \mathrm{O}_{3}$ promotes only a minimal conversion from $\mathrm{B}^{[\mathrm{III}]}$ to $\mathrm{B}^{[\mathrm{IV}]}$ coordination.

Finally, a broadband at higher values of wavenumbers between 1200 and $1500 \mathrm{~cm}^{-1}$ is also observed. This broadband is assigned to the overlapping of the vibrational modes (i) at $1240 \mathrm{~cm}^{-1}$ due to the $\mathrm{B}-\mathrm{O}$ symmetric stretching in $\mathrm{BO}_{3}$ units from pyro- and orthoborate groups, (ii) at $1340 \mathrm{~cm}^{-1}$ due to the $\mathrm{B}-\mathrm{O}$ stretching in $\mathrm{BO}_{3}$ units from different types of borate groups, and (iii) at $1470 \mathrm{~cm}^{-1}$ due to the $\mathrm{B}-\mathrm{O}^{-}$stretching in $\mathrm{BO}_{2} \mathrm{O}^{-}[35,35,43,44]$. For the samples with $\mathrm{Gd}_{2} \mathrm{O}_{3}$ concentrations higher than 5 mol\%, the last shoulder located at $1460 \mathrm{~cm}^{-1}$ is no longer visible, while the shoulder centered at $1340 \mathrm{~cm}^{-1}$ and the peak at $1240 \mathrm{~cm}^{-1}$ shift to low wavenumbers and are equal to 1312 and $1164 \mathrm{~cm}^{-1}$, respectively.

Fig. 9 shows the normalized XANES spectra of all glasses for the Ge-K absorption edge at 11103 eV (upper) and Gd- $\mathrm{L}_{\mathrm{III}}$ absorption edge at $7243 \mathrm{eV}$ (bottom). Due to the amorphous characteristic of vitreous materials, the analysis of XANES spectra was performed by comparing the sample with the standard crystalline compounds under analysis. We used the $\mathrm{XANES}$ spectra of the GeO $\mathrm{O}_{2}$ tetragonal and $\mathrm{Gd}_{2} \mathrm{O}_{3}$ cubic precursors as well as the crystalline $\mathrm{GeO}_{2}$ in its hexagonal structure (Rutila) in order to synthesize the glass. The results show that the local symmetry of the elements $\mathrm{Ge}$ and $\mathrm{Gd}$ are invariant with respect to the amount of $\mathrm{Gd}_{2} \mathrm{O}_{3}$ in the system. The Ge atoms in the glass sample have a local structure similar to the tetragonal $\mathrm{GeO}_{2}$ reference sample, whereas the $\mathrm{Gd}$ atoms are predominantly in the $\mathrm{Gd}^{3+}$ state due to the similarity of the spectra to the cubic $\mathrm{Gd}_{2} \mathrm{O}_{3}$ reference compound. The EXAFS spectra and the Fourier transform magnitude results for the elements Ge and Gd corroborate the XANES results and show that the first coordination sphere is similar to the tetragonal $\mathrm{GeO}_{2}$ and cubic $\mathrm{Gd}_{2} \mathrm{O}_{3}$ samples. They are all shown in Figs. S3 and $\mathrm{S} 4$ of the Supplementary Information.

From the EXAFS data related to the first coordination sphere of the elements Ge and Gd, we performed simulations to determine the number of neighbors $(\mathrm{N})$, the interatomic distance $(\mathrm{R})$ of the $\mathrm{Ge}-\mathrm{O}$ and $\mathrm{Gd}-\mathrm{O}$ bonds and the extraction of important parameters, such as the Debye-Waller factor (structural disorder degree). The results are summarized in Table 2. The simulation results show that independent of the element of analysis, the glassy sample has the same coordination number as the crystalline ones, that is, the local structure around the elements Ge and Gd is composed by four and eight oxygen atoms around them, respectively. The interatomic distance between the elements Ge-O remains constant (within the error), and the Debye-Waller factor increases as a consequence of the germanate network depolymerization. On the other side, $\mathrm{Gd}-\mathrm{O}$ bond in the vitreous samples is greater than in the crystalline compound and decreases as the concentration of $\mathrm{Gd}_{2} \mathrm{O}_{3}$ increases while the value of the Debye-Waller factor is the same for all samples (within error).

In order to extract the $\mathrm{Gd}_{2} \mathrm{O}_{3}$ content from our glass with respect to the targeted concentration and to study the magnetic behavior of the samples, a magnetic susceptibility study was carried out.

Fig. 10 shows the temperature dependence of the magnetic mass susceptibility for all glasses. As expected, a paramagnetic behavior with an asymptotic behavior can be observed when the temperature tends to zero. All the data were fitted according to a modified Curie-Weiss law,

$$
\chi=\chi_{\text {diam }}+\frac{C}{T-\theta},
$$

allowing the estimation of the Curie constant (C) from the slope and the paramagnetic Curie temperature from the intercept as well as the diamagnetic susceptibility extraction (see Table 3). For xmol\% of $\mathrm{Gd}_{2} \mathrm{O}_{3}$, a targeted $\mathrm{Gd}^{3+}$ ion content of $2 \mathrm{x}$ mol\% is expected. From our analysis, we could see a quite good convergence between the targeted and the probed $\mathrm{Gd}^{3+}$ ion contents owing to our modified Curie-Weiss law.

The results also confirm the paramagnetic characteristic of the $\mathrm{Gd}^{3+}$ ions, which were expected to be dispersed throughout the glass structure without forming clusters. As shown in Fig. 1b, the glasses in this system are attracted by a magnet. Such observation is in accordance with the fact that $\mathrm{Gd}^{3+}$ ions are free to align themselves along the magnetic field of a magnet. Once the magnetic field is not present anymore, no magnetic behavior is observed.

This property is very interesting for magneto-optical applications. However, it is out of the scope of this paper to describe all optical and magnetic properties of such glasses. These features are under investigation in our laboratories and the results will be soon reported.

\section{Conclusion}

This work evidenced targeted glass compositions for magneto-optical applications as well as the thermal and structural modifications of germanoborate glasses upon the addition of the paramagnetic $\mathrm{Gd}^{3+}$ ions were elucidated. 
We successfully obtained glasses in the system $\mathrm{GeO}_{2}-\mathrm{B}_{2} \mathrm{O}_{3}-\mathrm{Na}_{2} \mathrm{O}-\mathrm{Al}_{2} \mathrm{O}_{3}-\mathrm{PbO}$ with high concentration of $\mathrm{Gd}_{2} \mathrm{O}_{3}$. The glass matrix of the system under analysis accepted up to $\sim 20 \mathrm{~mol} \%$ of gadolinium oxide. Besides showing some valuable optical properties, such as good transparency and colorless, another interesting characteristic of such system is its behavior in the presence of a magnet, as it is attracted at room temperature and adheres to it. The attraction is proportional to concentration of $\mathrm{Gd}^{3+}$. Compositions with $\sim 5$, 10 and $15 \mathrm{~mol} \%$ of $\mathrm{Gd}_{2} \mathrm{O}_{3}$ showed good glass stability against crystallization $\left(>100{ }^{\circ} \mathrm{C}\right)$, which combined with their magnetic characteristics make such compositions very promising for the manufacture of optical fibers. Furthermore, the optical and electron micrographs together with the EDS analysis showed that the element Gd is dispersed in all crystalline phases of the sample with $15 \mathrm{~mol} \%$ of $\mathrm{Gd}_{2} \mathrm{O}_{3}$ that underwent non-isothermal heat treatment up to $950{ }^{\circ} \mathrm{C}$, making this composition rather important for a systematic crystallization study for the manufacture of transparent glass-ceramics.

Analyzing both Raman and infrared spectra together, we could observe that the presence of $\mathrm{Gd}_{2} \mathrm{O}_{3}$ affects both germanate and borate networks, mainly favoring the formation of small germanium rings and non-bridging oxygen groups, thus increasing the average strength in the chemical bonds and consequently producing higher connectivity of the network. The experimental evidence regarding the formation of 3-membered rings and the conversion of a small fraction of $\mathrm{B}^{[\mathrm{III}]}$ to $\mathrm{B}^{[\mathrm{IV}]}$ supports the jump to the higher temperature observed in the $\mathrm{Tg}$ for samples containing more than $5 \mathrm{~mol} \%$ of $\mathrm{Gd}_{2} \mathrm{O}_{3}$.

X-ray Absorption Near Edge Structure (XANES) and Extended X-ray Absorption Fine Structure (EXAFS) results showed that the local symmetry of the elements $\mathrm{Ge}$ and $\mathrm{Gd}$ are invariant to the amount of $\mathrm{Gd}_{2} \mathrm{O}_{3}$ and were found in the same coordination of their respective crystalline compounds, that is, $\mathrm{Ge}^{[\mathrm{VI}]}$ coordination and $\mathrm{Gd}^{3+}$ state, respectively. However, based on a simulation from EXAFS data, we can affirm that the Debye-Waller factor increases as a result of the depolymerization of the Ge-O network, even though the interatomic distance between Ge-O remains constant and is equal to $1.74 \AA$. In addition, when the Gd-O distance decreases from 2.35 to $2.32 \AA$ and the Debye-Waller factor remains constant, it seems that the structural distortion around the element $\mathrm{Gd}$ decreases with the increase in the amount of $\mathrm{Gd}_{2} \mathrm{O}_{3}$ within the glass network.

The magnetic measurements confirms the presence of only paramagnetic species and rules out the formation of nanodomains containing Gd.

Declaration of competing interest: The authors declare that they have no known competing financial interests or personal relationships that could have appeared to influence the work reported in this paper.

Acknowledgement: The authors wish to thank the financial support from the São Paulo Research Foundation (FAPESP), grants numbers 2013/07793-6, 2019/01223-0, and the Coordination for the Improvement of Higher Education Personnel (CAPES) for the postdoctoral fellowship grant.

\section{References}

1. Z.X. Mo, H.W. Guo, P. Liu, Y.D. Sheen, D.N. Gao. Luminescence properties of magneto-optical glasses containing Tb ${ }^{3+}$ ions. J. All. and Comp., 658 (2016), pp. 967-972.

2. J.D. Ambekar, R.P. Panmand, R.S. Sonawane, S.K. Apte, D.G. Hundiwale, B.B. Kale. Preparation of magneto-optical properties of stable bismuth phosphate nanoparticles in phosphate glass. RSC Adv., 5 (2015), pp. 48112-48117.

3. B. Bellanger, Y. Ledemi, Y. Messaddeq. Fluorophosphate glasses with high terbium content for magneto-optical applications. J. Phys. Chem. C. DOI: 10.1021/acs.jpcc.9b11696.

4. E. Golis, M. Reben, B.B. Gwizdala, J. Filipecki, J. Cisowski, P. Pawlik. Influence of lanthanum on structural and magneto-optic properties of diamagnetic glasses of the $\mathrm{TeO}_{2}$-WO3-PbO system. RSC Adv., 5 (2015), pp. 102530-102534.

5. S. Wu, B. Wu. Simulation model of magneto-optic fiber Bragg gratings and ist applications in Sagnac interferometers. Front. Optoelectron., 3 (2010), pp. 359-363.

6. S.M. Fadzil, P. Hrma, J. Crum, K.K. Siong, M.F. Ngatiman, R.M. Said. The formation in glasses containing rare earth oxides. AIP Conf. Proc., 175 (2014), p. 1584.

7. I.N. Chakraborty, D.E. Day. Effect of $\mathbf{R}^{3+}$ ions on the structure and properties of lanthanum borate glasses. J. Am. Ceram. Soc., 68 (1985), pp. 641-645.

8. J. Kaewkhao, N. Wantana, S. Kaewjaeng, S. Kothan, H.J. Kim. Luminescence characteristics of Dy3+ doped $\mathbf{G d}_{2} \mathbf{O}_{3}-\mathrm{CaO}_{-}-\mathrm{SiO}_{2}-$ $\mathbf{B}_{2} \mathbf{O}_{3}$ scintillating glasses. J. Rar. Earth.s, 34 (2016), pp. 583-589.

9. Y. Al-Hadeethi, M.I. Sayyed, J. Kaewkhao, A. Askin, B.M. Raffah, E.M. Mkawi, R. Rajaramakrishna. Physical, structural, optical, and radiation shielding properties of $\mathrm{B}_{2} \mathrm{O}_{3}-\mathrm{Gd}_{2} \mathrm{O}_{3}-\mathrm{Y}_{2} \mathrm{O}_{3}$ glass system. Appl. Phys. A, 125 (2019), p. 852.

10. N. Wantana, Y. Ruangtaweep, S.C. Kang, H.J. Kim, S. Kothan, J. Kaewkhao. Development of WO3-Gd $\mathbf{G d}_{2} \mathbf{O}_{3}-\mathbf{B}_{2} \mathrm{O}_{3}$ high density glasses doped with $\mathrm{Dy}^{\mathbf{3}+}$ for photonics and scintillation materials application. Solid State Sci., 101 (2020), Article 106135.

11. M.R. Prakash, G. Neelima, V.K. Kummara, N. Ravi, C.S.D. Viswanath, T.S. Rao, S.M. Jilani. Holmium doped bismuth-germanate glasses for green lighting applications: a spectroscopic study. Opt. Mater., 94 (2019), pp. 436-443.

12. M. Gökce, D. Kocyigit. Structural and optical properties of $\mathbf{G d}^{+3}$ doped $\mathrm{Bi}_{2} \mathbf{O}_{3}-\mathbf{G e O}_{2}$ glasses and glass-ceramics. Mater. Res. Express, 6 (2019), Article 025203.

13. H. Luo, X. Hu, W. Liu, Y. Zhang, A. Lu, X. Hao. Compositional dependence of properties of $\mathrm{Gd}_{2} \mathrm{O}_{3}-\mathrm{SiO}_{2}-\mathrm{B}_{2} \mathrm{O}_{3}$ glasses with high $\mathbf{G d}_{2} \mathbf{O}_{3}$ concentration. J. Non-Crys. Sol., 389 (2014), pp. 86-92. 
14. J. Fu, J.M. Parker, R.M. Brown, P.S. Flower. Compositional dependence of scintillation yield of glasses with high $\mathbf{G d d}_{2} \mathrm{O}_{3}$ concentrations. J. Non-Crys. Sol., 326-327 (2003), pp. 335-338.

15. S. Ju, J. Kim, K. Linganna, P.R. Watekar, S.G. Kang, B.H. Kim, S. Boo, Y. Lee, Y.H. An, C.J. Kim, W. Han. Temperature and vibration dependence of the faraday effect of $\mathbf{G d}_{2} \mathbf{O}_{3}$ NPs-doped alumino-silicate glass optical fiber. Sensors, 18 (2018), p. 988.

16. V.I. Savinkov, V.N. Sigaev, N.V. Golubev, P.D. Sarkisov, A.V. Masalov, A.P. Sergeev. Borogermanate glasses with a high terbium oxide content. J. Non-Crys. Sol., 356 (2010), pp. 1655-1659.

17. X. Sun, D. Jiang, S. Chen, G. Zheng, S. Huang, M. Gu, Z. Zhang, J. Zhao. Eu ${ }^{3+}$-Activated borogermanate scintillating glass with a high $\mathbf{G d}_{2} \mathbf{O}_{3}$ content. J. Am. Ceram. Soc., 95 (2013), pp. 1483-1489.

18. X. Sun, D. Jiang, W. Wang, C. Cao, Y. Li, G. Zhen, H. Wang, X. Yang, H. Chen, Z. Zhang, J. Zhao. Luminescence properties of B2O3-GeO2-Gd2O3 scintillating glass doped with rare-earth and transition-metal ions. Nuc. Inst. Methd. Phys res. A, 716 (2013), pp. 90-95.

19. R.G. Fernandes, P. Valle, D.F. Franco, M. Nalin. Crystallization kinetics study of silver-doped germanate glasses. Thermochim. Acta, 673 (2018), pp. 40-52.

20. A. Michalowicz, J. Moscovici, D. Muller-Bouvet, K. Provost. J. Phys. Conf., 190 (2009), Article 012034.

21. A. Michalowicz, J. Moscovici, D. Muller-Bouvet, K. Provost. J. Phys. Conf., 430 (2013), Article 012016.

22. A.L. Ankudinov, B. Ravel, S.D. Conradson, J.J. Rehr. Phys. Rev. B, 58 (1998), p. 7565.

23. J.J. Rehr, J.J. Kas, F.D. Vila, M.P. Prange, K. Jorissen. Phys. Chem. Chem. Phys., 12 (21) (2010), pp. 5503-5513.

24. IXS Standards and Criteria Subcommittee Reports, International XAFS Society (2000). http://ixs.iit.edu/subcommittee_reports/sc/

25. J. Ren, H. Eckert. Quantification of short and medium-range order in mixed network former glasses of the system $\mathrm{GeO}_{2}-$ $\mathrm{NaPO}_{3}$ : a combined NMR and X-ray photoelectron spectroscopy study. J. Phys. Chem. C, 116 (2012), pp. 12747-12763.

26. G.S. Henderson, L.G. Soltay, H.M. WangQ speciation in alkali germanate glasses. J. Non-Cryst. Solids, 356 (2010), pp. $2480-2485$.

27. G.S. Henderson, M.E. Fleet. The structure of glasses along the $\mathbf{N a}_{2} \mathbf{O}-\mathbf{G e O}_{2}$ join. J. Non-Cryst. Solids, 134 (1991), pp. $259-269$.

28. M. Micoulaut, L. Cormier, G.S. Henderson. The structure of amorphous, crystalline and liquid GeO2. J. Phys. Condens. Matter, 18 (2006), pp. R753-R784.

29. T.N. Ivanova, V.N. Bykov. Raman spectroscopy of glasses and melts of the $\mathrm{Na}_{2} \mathrm{O}-\mathrm{GeO}_{2}$ system. R.uss. Metall., 8 (2010), pp. 678680.

30. G.S. Henderson, H.M. Wang. Germanium coordination and the germanate anomaly. Eur. J. Mineral, 14 (2002), pp. $733-744$.

31. S.K. Sharma, D.W. Matson. Raman spectra and structure of sodium aluminogermanate glasses. J. Non-Cryst. Solids, 69 (1984), pp. 81-96.

32. S.J.L. Ribeiro, J.D. expert-Ghys, B. Piriou, V.R. Mastelaro. Structural studies in lead germanate glasses: EXAFS and vibrational spectroscopy. J. Non-Cryst. Solids, 159 (1993), pp. 213-221.

33. D. Di Martino, L.F. Santos, A.C. Marques, R.M. Almeida. Vibrational spectra and structure of alkali germanate glasses. J. NonCryst. Solids, 293-295 (2001), pp. 394-401.

34. O.K. Koroleva, M.V. Shtenberg, R.T. Zainullina, S.M. Lebedeva, L.A. Nevolina. Vibrational spectoscopy and density og K $\mathbf{K}_{2} \mathbf{O}-$ $\mathbf{B}_{2} \mathrm{O}_{3}-\mathrm{GeO}_{2}$ glasses with variable B/Ge ratio. Phys. Chem. Chem. Phys., 21 (2019), pp. 12676-12684.

35. I.N. Chakraborty, R.A. Condrate Sr. The vibrational spectra of $\mathbf{B}_{2} \mathbf{O}_{3}-\mathbf{G e O}_{2}$ glasses. J. Non-Cryst. Solids, 81 (1986), pp. $271-284$.

36. G.D. Chryssikos, D.E. Turcotte, R.V. Mulkern, P.J. Bray, W.M. Reisen Jr. Infrared study of cadmium borogermamete glasses. J. Non-Cryst. Solids, 81 (1986), pp. 54-68.

37. G.D. Chryssikos, E.I. Kamitsos, W.M. Reisen Jr. A Raman investigation of cadmium borate and borogermanate glasses. J. NonCryst. Solids, 95 (1987), pp. 155-168.

38. M. Montesso, D. Manzani, J.P. Donozo, C.J. Magon, I.D.A. Silva, M. Chiesa, E. Morra, M. Nalin. Synthesis and strucutural characterization of a new SbPO4-GeO2 glass system. J. Non-Cryst. Solids, 500 (2018), pp. 133-140.

39. B.N. Meera, J. Ramakrishna. Raman spectral studies of borate glasses. J. Non-Cryst. Solids, 159 (1993), pp. 1-21.

40. R. El Hayek, F. Ferey, P. Florian, A. Pisch, D.R. Neuville. Structure and properties of lime alumino-borate glasses. Chem. Geol., 461 (2017), pp. 75-81.

41. S. Rada, E. Culea. Structural and optical properties in gadolinium-aluminum-lead-germanate quaternary glasses. J. Non-Cryst. Solids, 357 (2011), pp. 1724-1728.

42. S. Rada, M. Rada, E. Culea. Structural and optical properties of the gadolinium-lead-germanate glasses. J. Non-Cryst. Solids, 357 (2011), pp. 62-66.

43. P. Pascuta, E. Culea. Structural and thermal properties of some zinc borate glasses containing gadolinium ions. J. Mater. Sci. Mater. Electron., 22 (2011), pp. 1060-1066.

44. S. Rada, M. Culea, M. Rada, P. Pascuta, V. Maties, E. Culea. The double role played by the $\mathbf{G d}_{2} \mathbf{O}_{3}$ in the gadolinium-aluminumborate-bismuthate quaternary glass-forming tendency. GdBO$_{3}$ crystalline phase. J. Mol. Struct., 937 (2009), pp. $70-74$.

45. C. Le Luyer, A. García-Murillo, E. Berstein, J. Mugnier. Waveguide Raman spectroscopy of sol-gel Gd $\mathbf{G}_{3} \mathrm{O}_{3}$ thin films. J. Raman Spectrosc., 34 (2003), pp. 234-239.

46. G.S. Henderson. The germanate anomaly: what do we know? J. Non-Cryst. Solids, 353 (2007), pp. 1695-1704. 
Table 1

Compositions, characteristic temperatures $\mathrm{T}_{\mathrm{g}}$ and $\mathrm{T}_{\mathrm{x}}$, and glass stability against crystallization parameter, $\mathrm{T}_{\mathrm{x}}-\mathrm{T}_{\mathrm{g}}$.

\begin{tabular}{llll}
\hline Samples & $\mathrm{T}_{\mathrm{g}}\left[{ }^{\circ} \mathrm{C}\right] \mp 3^{\circ} \mathrm{C}$ & $\mathrm{T}_{\mathrm{x}}\left[{ }^{\circ} \mathrm{C}\right] \mp 3^{\circ} \mathrm{C}$ & $\mathrm{T}_{\mathrm{x}}-\mathrm{T}_{\mathrm{g}}\left[{ }^{\circ} \mathrm{C}\right] \mp 3^{\circ} \mathrm{C}$ \\
\hline $0 \mathrm{Gd}_{2} \mathrm{O}_{3}$ & 455 & 651 & 196 \\
$1 \mathrm{Gd}_{2} \mathrm{O}_{3}$ & 464 & - & $>500$ \\
$2 \mathrm{Gd}_{2} \mathrm{O}_{3}$ & 473 & - & $>500$ \\
$5 \mathrm{Gd}_{2} \mathrm{O}_{3}$ & 475 & 733 & 260 \\
$10 \mathrm{Gd}_{2} \mathrm{O}_{3}$ & 553 & 731 & 178 \\
$15 \mathrm{Gd}_{2} \mathrm{O}_{3}$ & 617 & 737 & 120 \\
$20 \mathrm{Gd}_{2} \mathrm{O}_{3}$ & 652 & 735 & 83 \\
\hline
\end{tabular}

Table 2

Parameter obtained from EXAFS simulation to determine the coordination number $(\mathrm{N})$, the interatomic distance $(\mathrm{R})$ and the Debye-Waller factor $\left(\sigma^{2}\right)$. The * indicates that $\mathrm{N}$ is fixed over the simulation.

\begin{tabular}{|c|c|c|c|c|c|c|}
\hline Bond & Sample & $\mathrm{N}$ (coordination number) & $\mathrm{R}$ (interatomic distance) $\AA$ & Debye-Waller factor $\left(\sigma^{2}\right)$ & $\Delta \mathrm{E}(\mathrm{eV})$ & QF \\
\hline $\mathrm{Ge}-\mathrm{O}$ & $\mathrm{GeO}_{2}$ tetragonal & $4^{*}$ & $1.734 \pm 0.004$ & $0.0028 \pm 0.0004$ & $1.2 \pm 0.5$ & 74 \\
\hline $\mathrm{Ge}-\mathrm{O}$ & $0 \mathrm{Gd}_{2} \mathrm{O}_{3}$ & $4.2 \pm 0.2$ & $1.742 \pm 0.005$ & $0.0034 \pm 0.0004$ & $0.3 \pm 0.6$ & 1.2 \\
\hline $\mathrm{Ge}-\mathrm{O}$ & $1 \mathrm{Gd}_{2} \mathrm{O}_{3}$ & $4.2 \pm 0.2$ & $1.745 \pm 005$ & $0.0029 \pm 0.0004$ & $0.6 \pm 0.5$ & 1.4 \\
\hline $\mathrm{Ge}-\mathrm{O}$ & $2 \mathrm{Gd}_{2} \mathrm{O}_{3}$ & $4.2 \pm 0.2$ & $1.741 \pm 0.005$ & $0.0036 \pm 0.0003$ & $0.4 \pm 0.5$ & 1.1 \\
\hline $\mathrm{Ge}-\mathrm{O}$ & $5 \mathrm{Gd}_{2} \mathrm{O}_{3}$ & $4.2 \pm 0.2$ & $1.741 \pm 0.004$ & $0.0038 \pm 0.0003$ & $0.4 \pm 0.4$ & 1.3 \\
\hline $\mathrm{Ge}-\mathrm{O}$ & $10 \mathrm{Gd}_{2} \mathrm{O}_{3}$ & $4.2 \pm 0.2$ & $1.745 \pm 0.005$ & $0.0038 \pm 0.0005$ & $0.3 \pm 0.5$ & 1.7 \\
\hline $\mathrm{Ge}-\mathrm{O}$ & $15 \mathrm{Gd}_{2} \mathrm{O}_{3}$ & $4.2 \pm 0.2$ & $1.746 \pm 0.006$ & $0.0038 \pm 0.0005$ & $0.2 \pm 0.6$ & 1.3 \\
\hline $\mathrm{Ge}-\mathrm{O}$ & $20 \mathrm{Gd}_{2} \mathrm{O}_{3}$ & $4.2 \pm 0.2$ & $1.744 \pm 0.005$ & $0.0038 \pm 0.0006$ & $0.3 \pm 0.5$ & 1.2 \\
\hline Gd-O & $\mathrm{Gd}_{2} \mathrm{O}_{3}$-cubic & $8^{*}$ & $2.29 \pm 0.01$ & $0.0075 \pm 0.000$ & $0.7 \pm 0.2$ & 1.3 \\
\hline $\mathrm{Gd}-\mathrm{O}$ & $1 \mathrm{Gd}_{2} \mathrm{O}_{3}$ & $8.2 \pm 0.6$ & $2.35 \pm 0.01$ & $0.015 \pm 0.001$ & $0.0 \pm 0.2$ & 1.6 \\
\hline $\mathrm{Gd}-\mathrm{O}$ & $2 \mathrm{Gd}_{2} \mathrm{O}_{3}$ & $8.2 \pm 0.5$ & $2.36 \pm 0.01$ & $0.016 \pm 0.001$ & $0.7 \pm 0.5$ & 1.5 \\
\hline Gd-O & $5 \mathrm{Gd}_{2} \mathrm{O}_{3}$ & $8.0 \pm 0.4$ & $2.35 \pm 0.01$ & $0.015 \pm 0.001$ & $0.0 \pm 0.3$ & 1.4 \\
\hline Gd-O & $10 \mathrm{Gd}_{2} \mathrm{O}_{3}$ & $8.1 \pm 0.3$ & $2.32 \pm 0.01$ & $0.015 \pm 0.001$ & $0.3 \pm 0.2$ & 1.7 \\
\hline Gd-O & $15 \mathrm{Gd}_{2} \mathrm{O}_{3}$ & $8.0 \pm 0.3$ & $2.32 \pm 0.01$ & $0.015 \pm 0.001$ & $0.3 \pm 0.2$ & 1.9 \\
\hline Gd-O & $20 \mathrm{Gd}_{2} \mathrm{O}_{3}$ & $8.1 \pm 0.4$ & $2.32 \pm 0.01$ & $0.016 \pm 0.001$ & $0.3 \pm 0.2$ & 1.9 \\
\hline
\end{tabular}

Table 3

Parameters obtained from Curie-Weiss fits of the magnetic susceptibility data for all glasses studied, where $C$ is the Curie constant and $\theta$ is the Weiss temperature.

\begin{tabular}{lllll}
\hline $\begin{array}{l}\text { Targeted } \\
\mathrm{Gd}^{3+} \text { ion } \\
\text { for } \mathrm{xmol}^{2} \\
\text { of } \mathrm{Gd}_{2} \mathrm{O}_{3}\end{array}$ & $\mathrm{C}(\mathrm{emu} . \mathrm{K} / \mathrm{mol})$ & $\theta(\mathrm{K})$ & $\begin{array}{l}\chi_{\text {diam }}\left(10^{-4}\right) \\
\mathrm{emu} / \mathrm{mol}\end{array}$ & $\begin{array}{l}\mathrm{Probed}_{\mathrm{Gd}^{3+}} \\
\text { ion }\end{array}$ \\
\hline $1 \%$ & $0.1295 \pm 0.0009$ & $-1.75 \pm 0.03$ & $5.34 \pm 0.24$ & $1.6 \%$ \\
$2 \%$ & $0.491 \pm 0.003$ & $-2.07 \pm 0.03$ & $-2.45 \pm 0.41$ & $6.2 \%$ \\
$05 \%$ & $0.92 \pm 0.01$ & $-2.00 \pm 0.08$ & $-6.9 \pm 2.0$ & $11.7 \%$ \\
$10 \%$ & $1.725 \pm 0.007$ & $-2.24 \pm 0.03$ & $-4.09 \pm 0.95$ & $21.8 \%$ \\
$15 \%$ & $2.50 \pm 0.02$ & $-2.33 \pm 0.06$ & $-10.9 \pm 2.9$ & $31.8 \%$ \\
$20 \%$ & $3.124 \pm 0.008$ & $-1.56 \pm 0.03$ & $-3.4 \pm 1.3$ & $39.6 \%$ \\
\hline
\end{tabular}




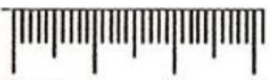

$0 \mathrm{~cm} \quad 1 \quad 2 \quad 3$
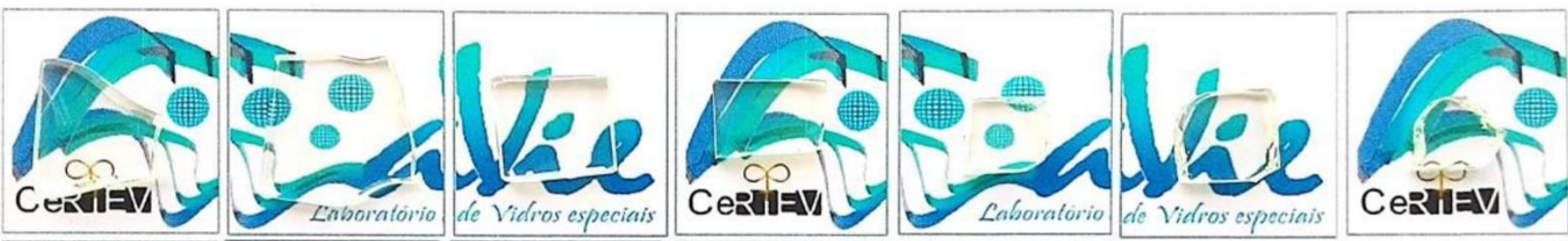

\section{$0 \mathrm{Gd}_{2} \mathrm{O}_{3} 1 \mathrm{Gd}_{2} \mathrm{O}_{3}$}

\section{$2 \mathrm{Gd}_{2} \mathrm{O}_{3}$}

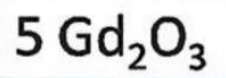

$10 \mathrm{Gd}_{2} \mathrm{O}_{3} 15 \mathrm{Gd}_{2} \mathrm{O}_{3}$

$20 \mathrm{Gd}_{2} \mathrm{O}_{3}$

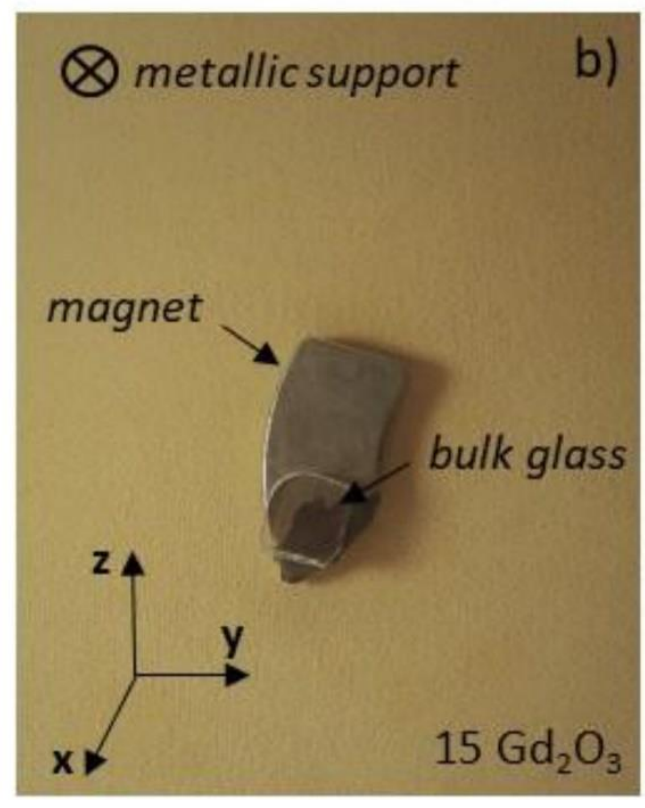

Fig. 1. (online color) a) Photograph of glasses with 0 up to 20 mol\% of $\mathrm{Gd}_{2} \mathrm{O}_{3}$ after cutting and polishing; b) sample with $15 \mathrm{~mol} \%$ of $\mathrm{Gd}_{2} \mathrm{O}_{3}$ attracted by the magnet on a metallic support fixed normal to the $x-y$ plane. (For interpretation of the references to color in this figure legend, the reader is referred to the Web version of this article.)

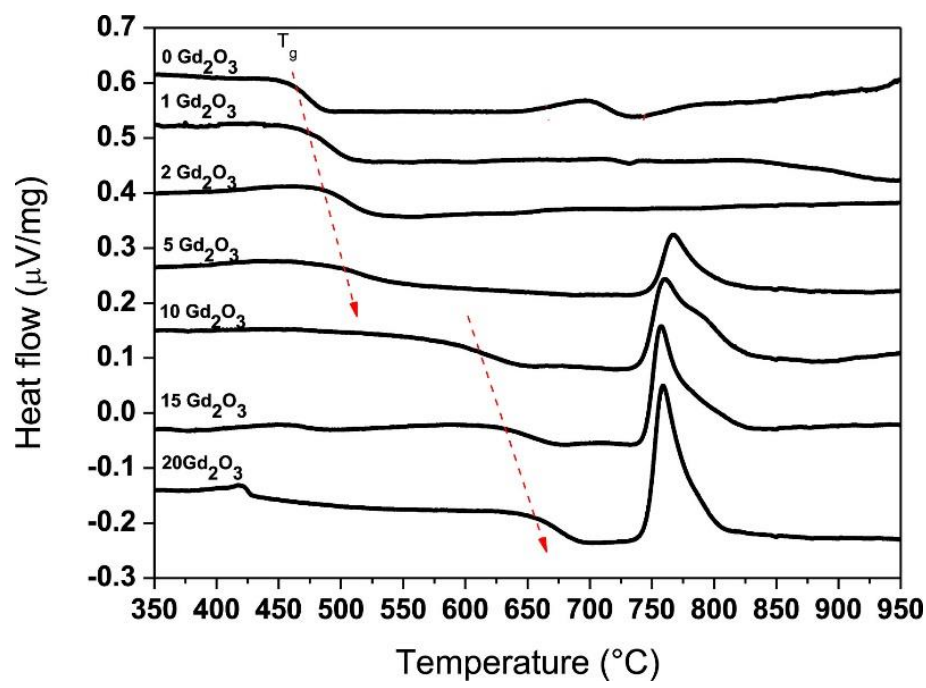

Fig. 2. DSC curves for samples with 0 - up to $20 \mathrm{~mol} \%$ of $\mathrm{Gd}_{2} \mathrm{O}_{3}$. The dashed red arrow represents the evolution of glass transition temperature $\left(\mathrm{T}_{\mathrm{g}}\right)$ as a function of composition. The exothermic events of low-intensity near to 450 and $415^{\circ} \mathrm{C}$ for the compositions with concentrations of 15 and 20 mol\% of $\mathrm{Gd}_{2} \mathrm{O}_{3}$, respectively, has not been characterized and their confirmation depends on the repetition of the analysis. (For interpretation of the references to color in this figure legend, the reader is referred to the Web version of this article.) 


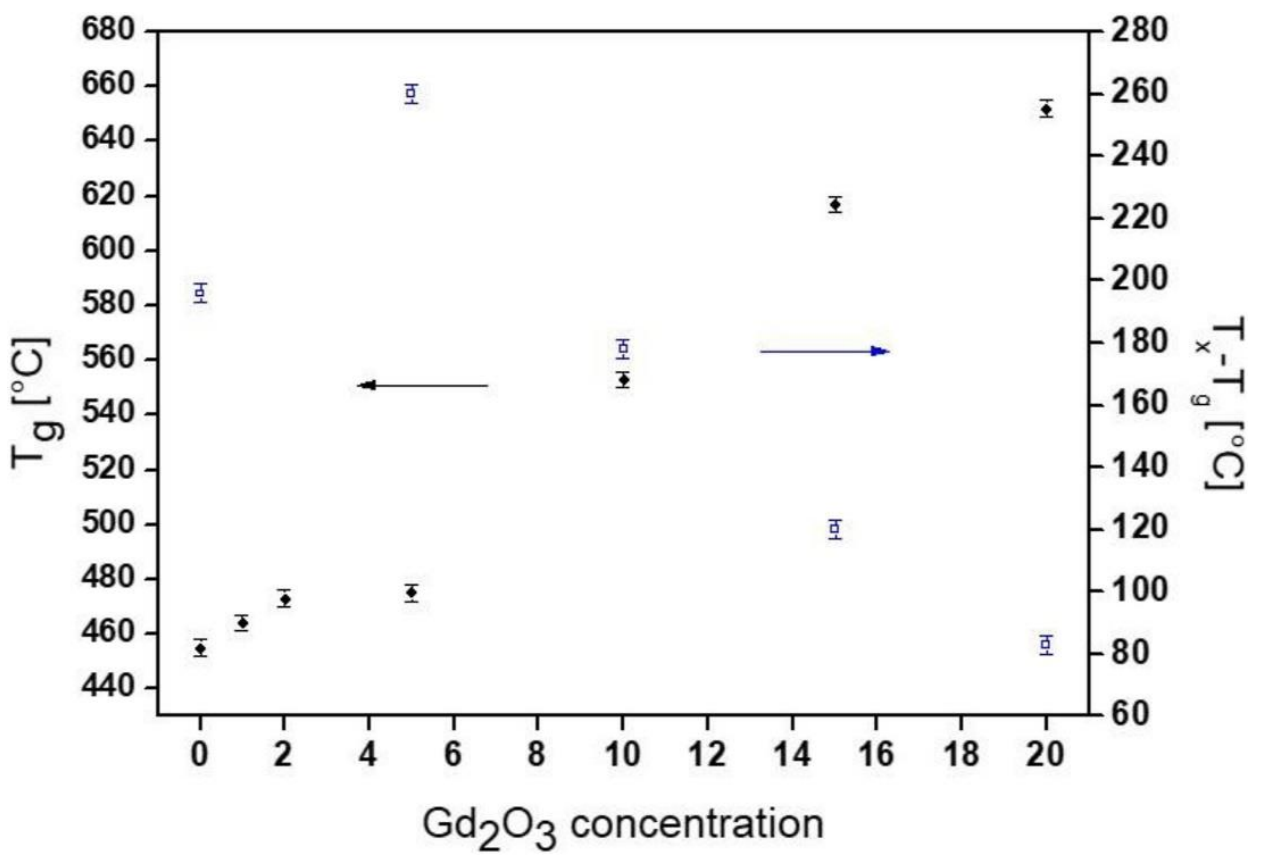

Fig. 3. Glass transition temperature (left) and glass stability parameter against crystallization (right) as a function of $\mathrm{Gd}_{2} \mathrm{O}_{3}$ concentration.
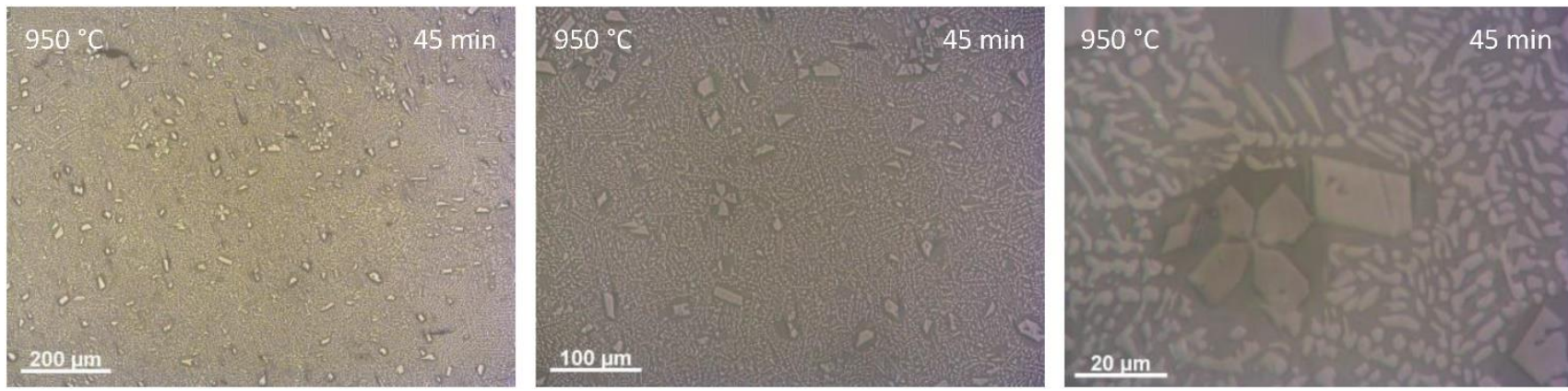

Fig. 4. Optical micrographs of a fully crystallized bulk sample with $15 \mathrm{~mol} \%$ of $\mathrm{Gd}_{2} \mathrm{O}_{3}$ non-isothermally heat-treated at $10{ }^{\circ} \mathrm{C} / \mathrm{min}$ up to $950{ }^{\circ} \mathrm{C}$ and kept in this temperature for $45 \mathrm{~min}$. The columns, from left to right, correspond to different magnifications. 

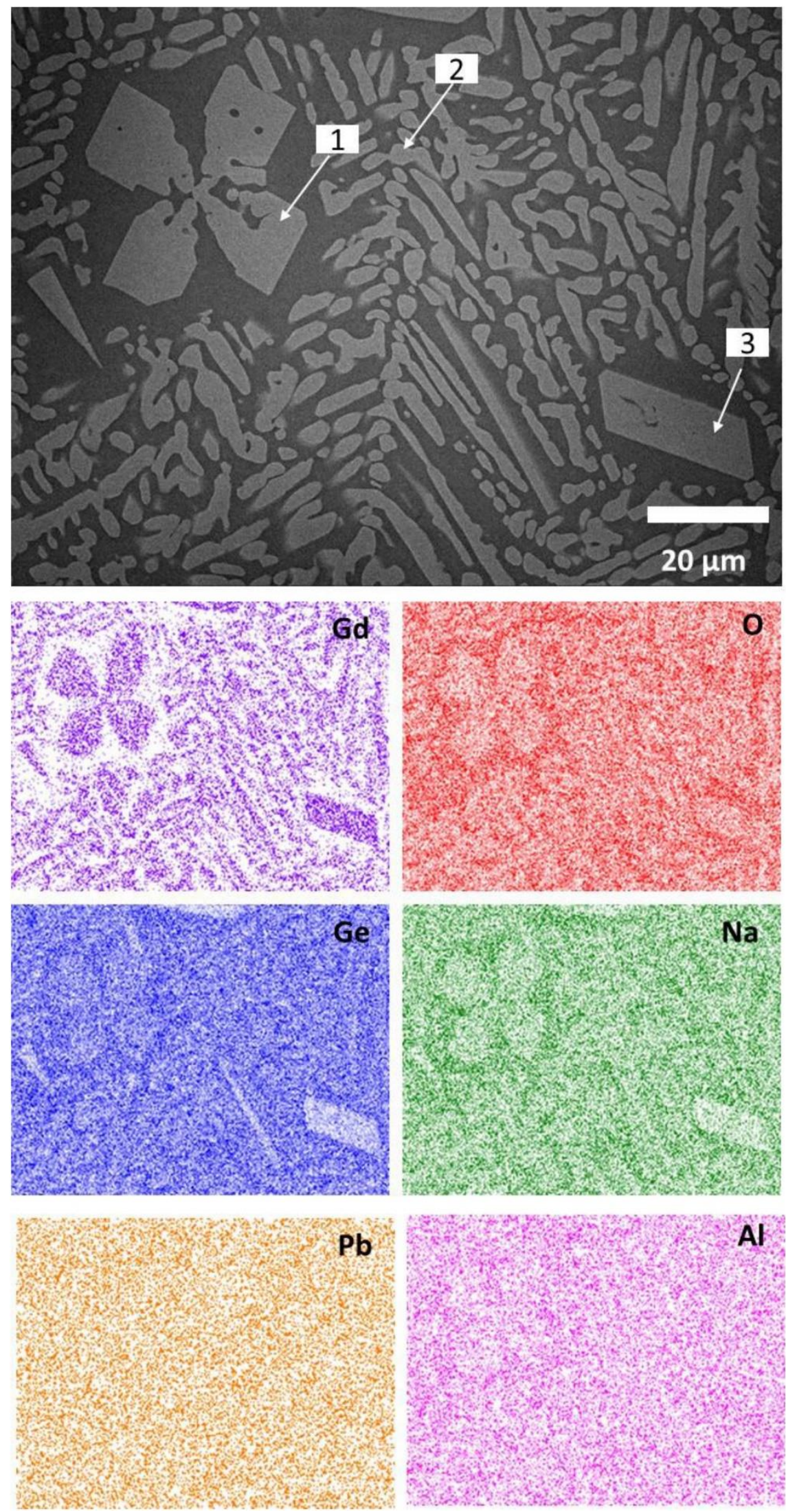

Fig. 5. (online color) (top) Scanning Electron Microscopy (SEM). The arrows represent the EDS analysis performed on the phases of the region. (bottom) Chemical mapping of the elements $\mathrm{Gd}, \mathrm{O}, \mathrm{Ge}, \mathrm{Na}, \mathrm{Pb}$ and $\mathrm{Al}$ of a glass-ceramics under non-isothermal heat treatment at $10^{\circ} / \mathrm{min}$ up to $950{ }^{\circ} \mathrm{C}$ followed by isothermal heat treatment of $45 \mathrm{~min}$ for the sample with 15 mol\% of $\mathrm{Gd}_{2} \mathrm{O}_{3}$.

(For interpretation of the references to color in this figure legend, the reader is referred to the Web version of this article.) 


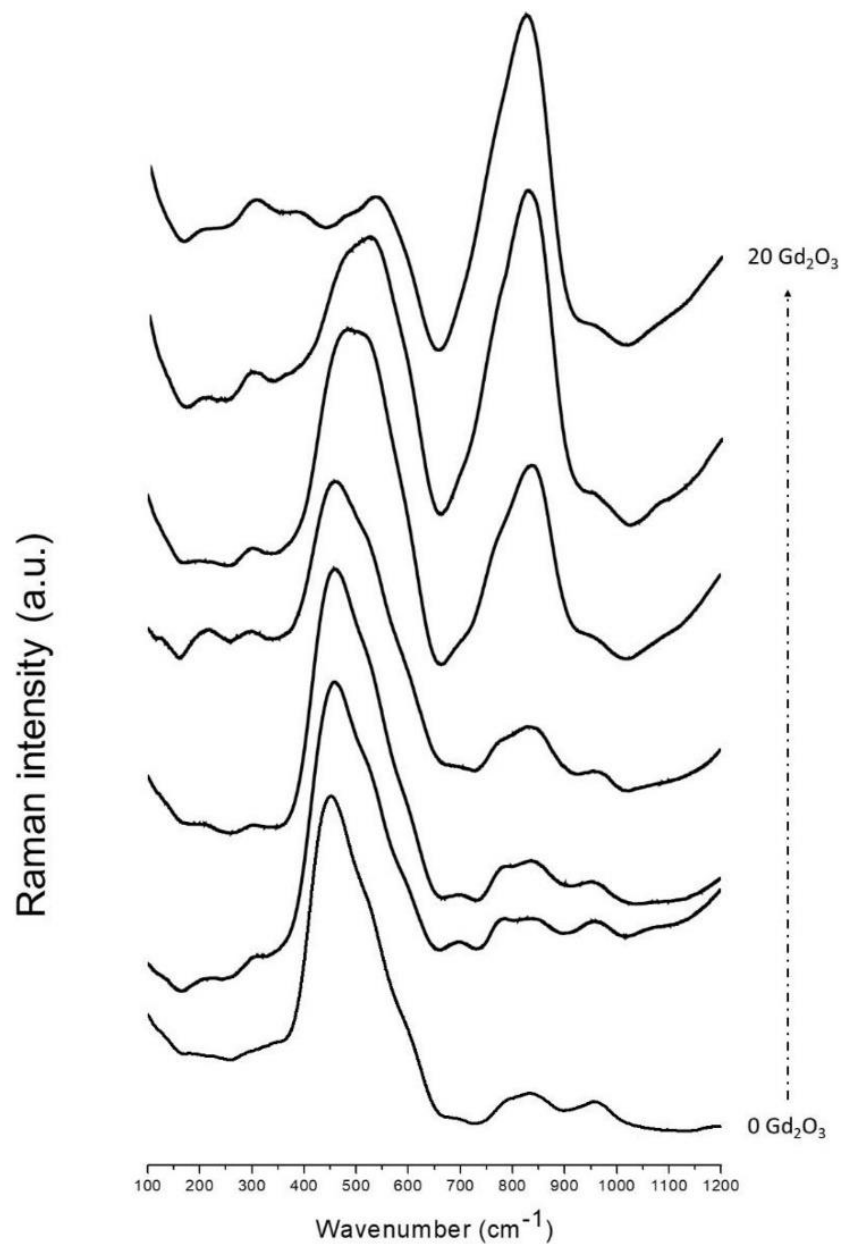

Fig. 6. Raman spectra of samples with $\mathrm{Gd}_{2} \mathrm{O}_{3}$ concentrations from 0 to 20 mol\%. 

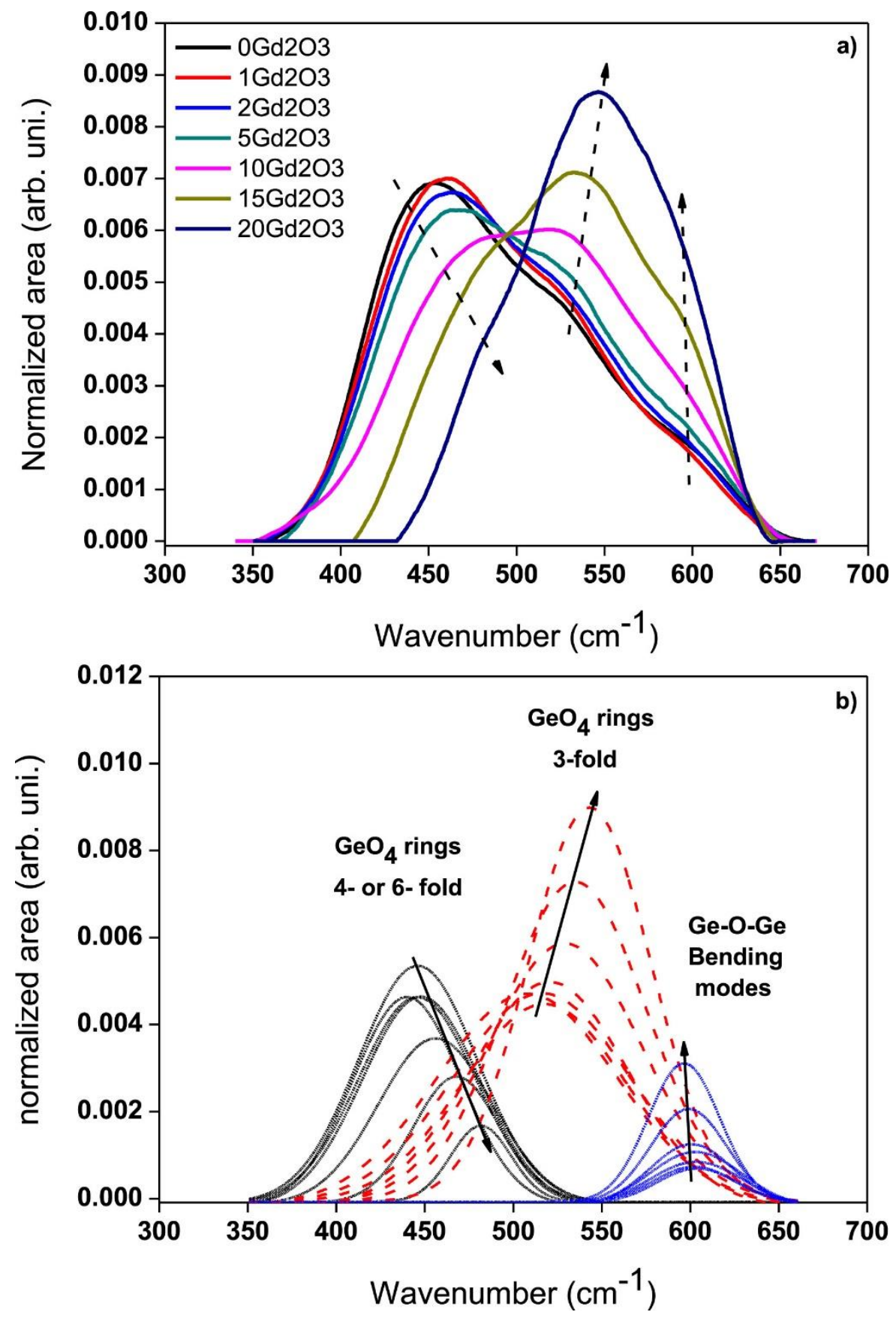

Fig. 7. (online color) a) Spectra magnification with area normalized for all samples in the region of $350-650 \mathrm{~cm}^{-1}$; b) deconvoluted bands. The dashed black, red and blue bands represent 4- or 6-fold rings, 3-fold rings and bending modes of Ge-OGe bonds, respectively. (For interpretation of the references to color in this figure legend, the reader is referred to the Web version of this article.) 


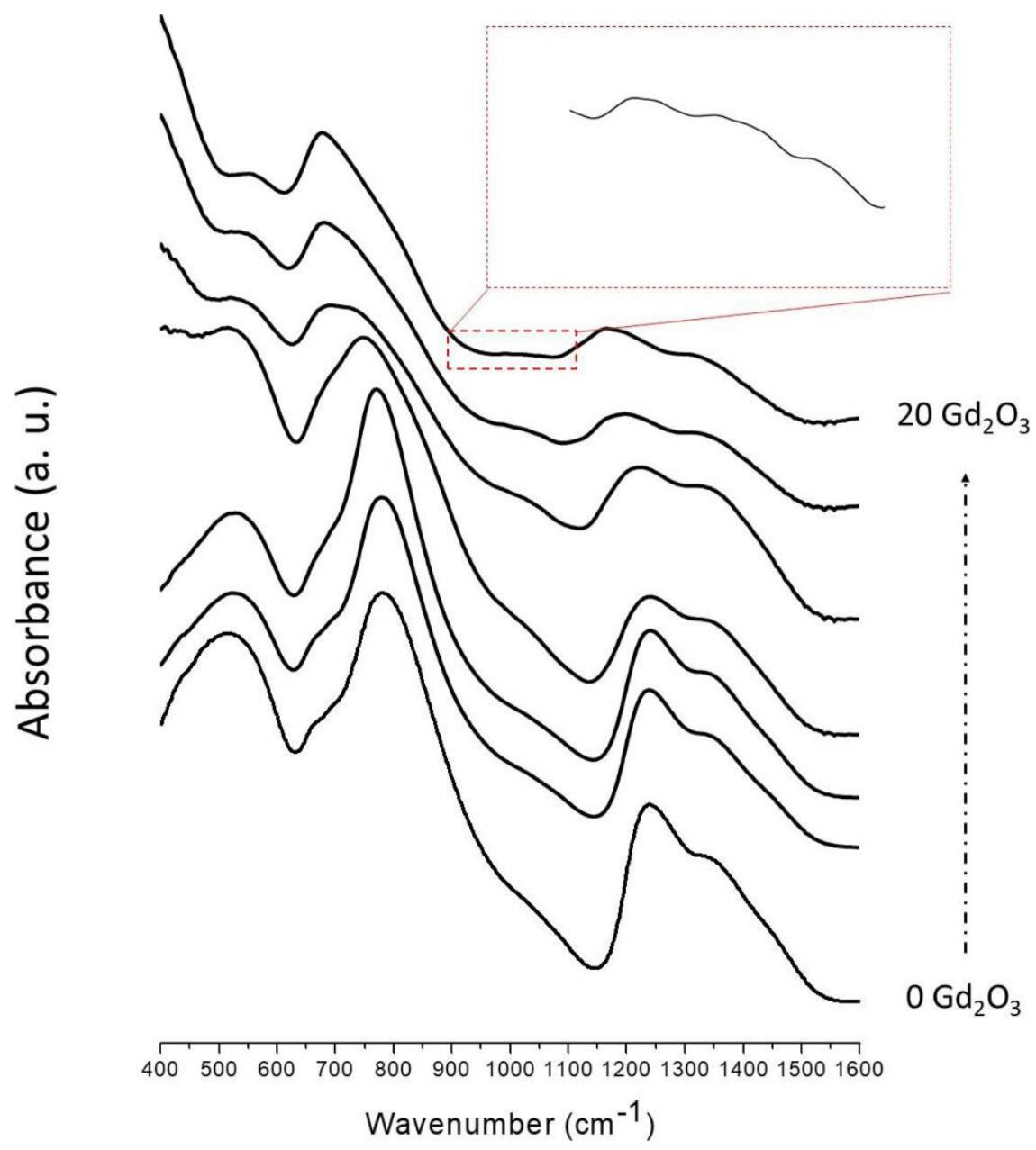

Fig. 8. Absorption spectra in the infrared range for samples with concentrations of $\mathrm{Gd}_{2} \mathrm{O}_{3}$ from 0 to 20 mol\%. The red dashed box is a magnification in the selected area of the spectrum for the sample with 20 mol\% of $\mathrm{Gd}_{2} \mathrm{O}_{3}$ to evidence the rise of three lowintensity peaks. (For interpretation of the references to color in this figure legend, the reader is referred to the Web version of this article.) 

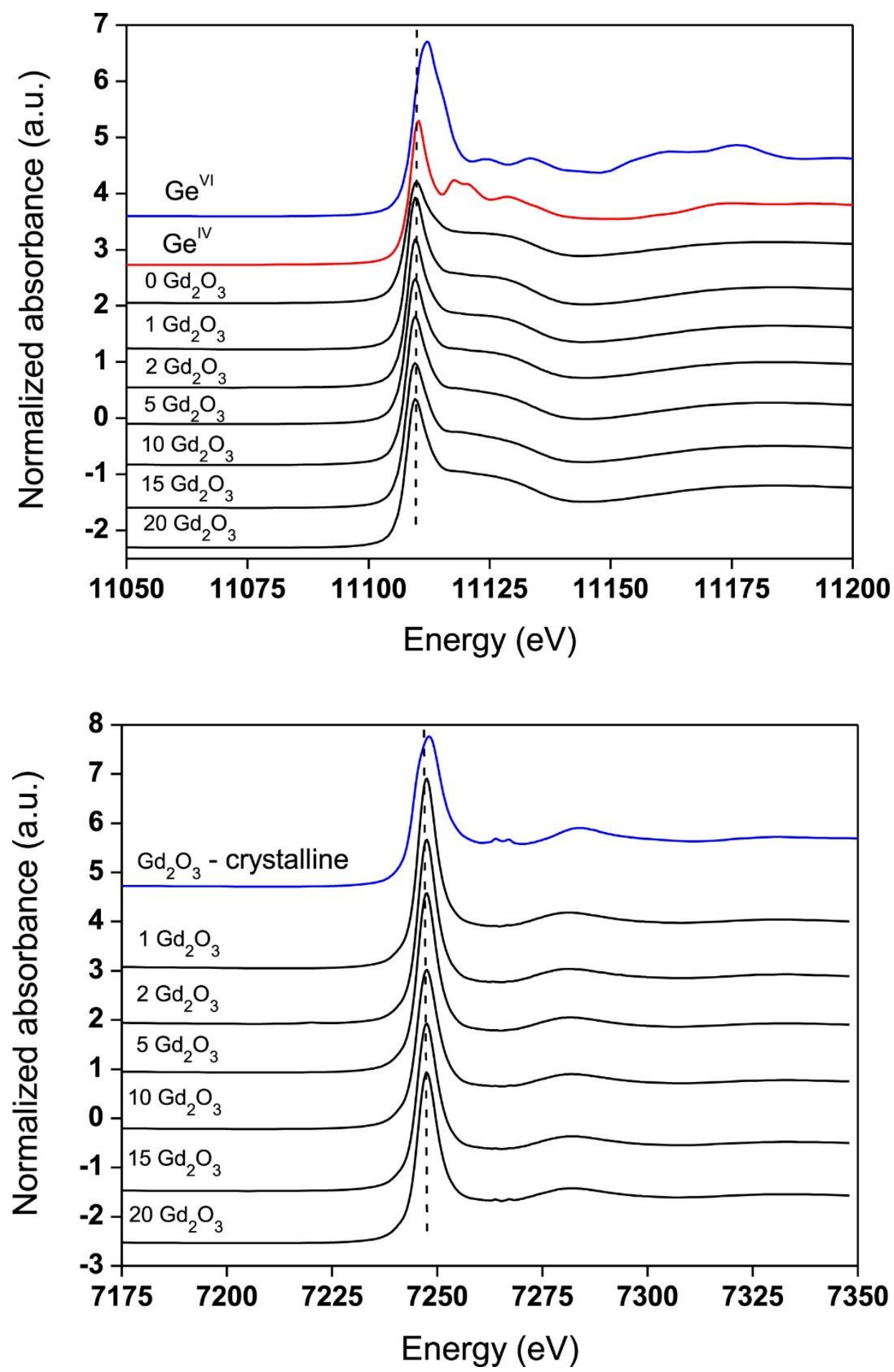

Fig. 9. Normalized X-ray absorption near-edge spectrum of all glasses. a) Ge-K absorption edge (11103 eV) and b) Gd-LIII absorption edge (7243 eV). 


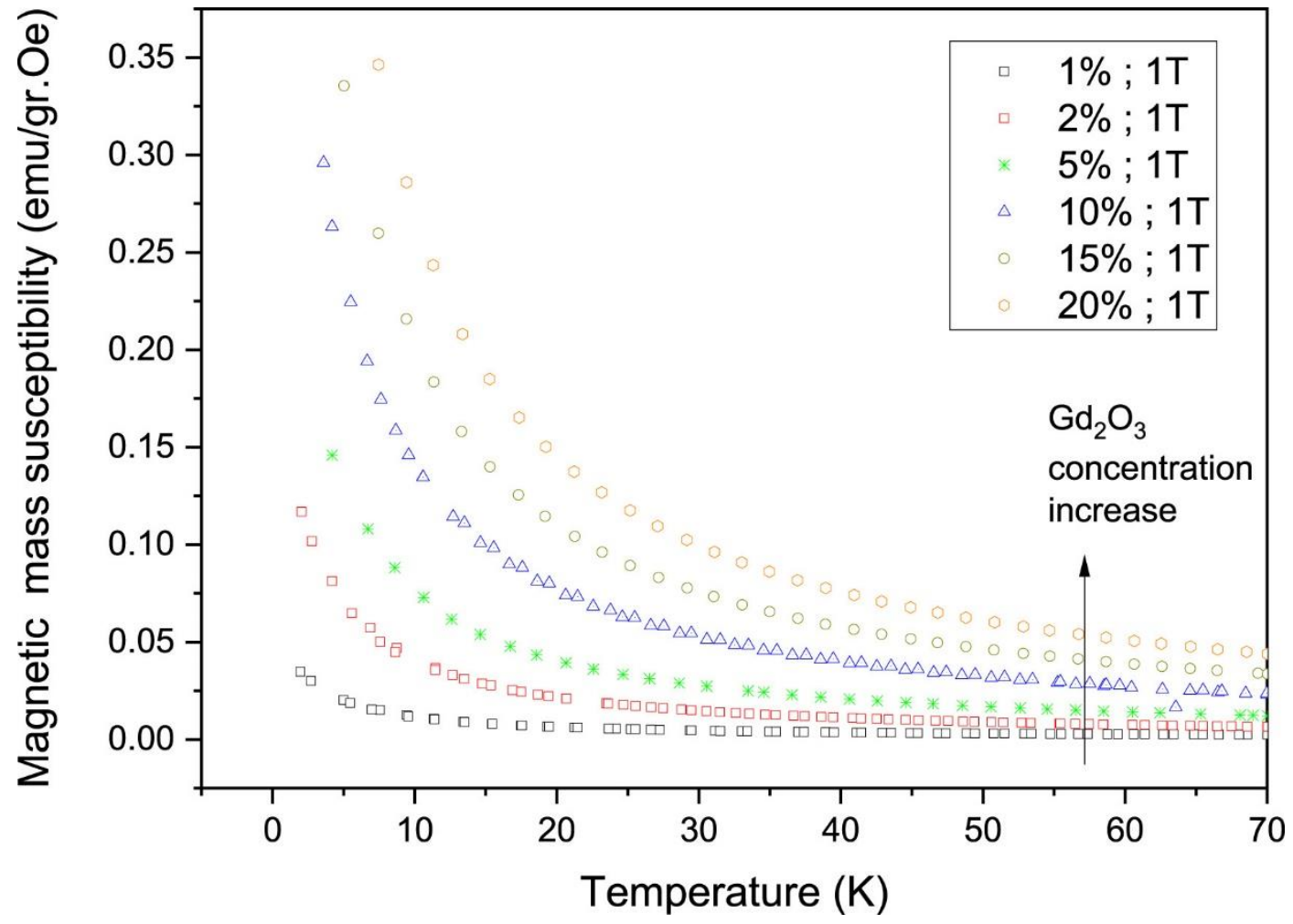

Fig. 10. Magnetic mass susceptibility $\left(\chi_{m}\right)$ vs temperature measurements for a series of glasses according to the $\mathrm{Gd}_{2} \mathrm{O}_{3}$ concentration. 